\title{
Modeling of Saharan dust outbreaks over the Mediterranean by RegCM3: case studies
}

\author{
M. Santese ${ }^{1}$, M. R. Perrone ${ }^{2}$, A. S. Zakey ${ }^{3}$, F. De Tomasi ${ }^{2}$, and F. Giorgi ${ }^{3}$ \\ ${ }^{1} \mathrm{CMCC}$ - Centro Euromediterraneo per i Cambiamenti Climatici, 73100, Lecce, Italy \\ ${ }^{2}$ CNISM, Physics Department, Università del Salento, 73100, Lecce, Italy \\ ${ }^{3}$ Abdus Salam International Centre for Theoretical Physics, 34100, Trieste, Italy
}

Received: 10 July 2009 - Published in Atmos. Chem. Phys. Discuss.: 17 September 2009

Revised: 3 December 2009 - Accepted: 6 December 2009 - Published: 11 January 2010

\begin{abstract}
The regional climate model RegCM3 coupled with a radiatively active aerosol model with online feedback is used to investigate direct and semi-direct radiative aerosol effects over the Sahara and Europe in a test case of July 2003. The aerosol model includes dust particles in addition to sulfates, hydrophobic and hydrophilic black carbon and organic carbon. The role of the aerosol online feedback on the radiation budget and the direct radiative forcing (short-wave and long-wave) by dust particles are investigated by intercomparing results from three experiments: REF, including all interactive aerosol components, Exp1, not accounting for the aerosol radiative feedback, and Exp2 not accounting for desert dust particles. The comparison of results in the REF experiment with satellite observations, sun/sky radiometer measurements, and lidar profiles at selected Central Mediterranean sites reveals that the spatio-temporal evolution of the aerosol optical depth is reasonably well reproduced by the model during the entire month of July. Results for the dust outbreaks of 17 and 24 July, averaged over the simulation domain, show that the daily-mean SW direct radiative forcing by all particles is $-24 \mathrm{Wm}^{-2}$ and $-3.4 \mathrm{Wm}^{-2}$ on 17 July and $-25 \mathrm{Wm}^{-2}$ and $-3.5 \mathrm{Wm}^{-2}$ on 24 July at the surface and top of the atmosphere, respectively. This is partially offset by the LW direct radiative forcing, which is $7.6 \mathrm{Wm}^{-2}$ and $1.9 \mathrm{Wm}^{-2}$ on 17 July and $8.4 \mathrm{Wm}^{-2}$ and $1.9 \mathrm{Wm}^{-2}$ on 24 July at the surface and top of the atmosphere, respectively. Hence, the daily-mean SW forcing is offset by the LW forcing of $\sim 30 \%$ at the surface and of $\sim 50 \%$ at the ToA. It is also shown that atmospheric dynamics and hence dust production and advection processes are dependent on the simulation assumptions and may significantly change within few tens of kilometers. The comparison of REF and Exp1 shows that the
\end{abstract}

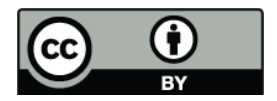

Correspondence to: $\mathrm{M}$. Santese (monica.santese@le.infn.it) aerosol online feedback on the radiation budget decreases the domain-average daily-mean value of the $2 \mathrm{~m}$-temperature, aerosol column burden (CB), and short-wave (SW) atmospheric forcing by $-0.52^{\circ} \mathrm{C}, 14 \%$, and $0.9 \%$, respectively on 17 July and by $-0.39^{\circ} \mathrm{C}, 12 \%$ and $12 \%$, respectively on 24 July. The comparison of REF and Exp2 reveals that on 17 July, radiatively-active dust particles decrease the dailymean $2 \mathrm{~m}$-temperature averaged over the whole simulation domain by $0.4 \%$ even if are responsible for $99.8 \%$ and $97 \%$ of the daily-mean aerosol column burden and SW atmospheric forcing, respectively.

\section{Introduction}

The influence of aerosols on the Earth's climate is not yet adequately taken into account in climate models. As a consequence, research activities aimed at improving the aerosol representation in climate models are essential for a more accurate prediction of climatic changes. Indeed, an advanced, multi-disciplinary approach that integrates surface and space-based measurements with models needs to be developed to achieve the goal of reducing uncertainties in aerosol impacts on climate (US Climate Change Science Program; Chin et al., 2009). The Mediterranean basin has a particular relevance in aerosol-climate studies, as this area is particularly affected by air pollution. In addition to seaspray aerosols, mineral dust and biomass burning particles from Northern and Central Africa, long-range transported urban/industrial and biomass burning aerosols from Northern and Eastern Europe converge over the Mediterranean. As a consequence, several studies indicate that the aerosol radiative forcing is among the highest in the world during Mediterranean summers (e.g. Lelieveld et al., 2002; Andreae et al., 2002). In addition, Giorgi (2006) identified

Published by Copernicus Publications on behalf of the European Geosciences Union. 
the Mediterranean as one of the most responsive regions to GHG-induced global climate change, so that the aerosol forcing is expected to strongly interact with the GHG forcing over this region.

Mineral dust is among the major aerosol components over the Mediterranean, however its radiadive impact is still not well defined. The net perturbation of the radiation balance (solar and terrestrial) imposed by mineral dust (i.e. the dust radiative forcing) is complex (Sokolik et al., 2001) due to its scattering, absorption, and emission properties. Sign and magnitude of the direct dust radiative forcing are controlled by the dust optical properties, which depend on the dust size distribution and refractive index. The latter in turn depends on the mineral composition and particle mixing state, which might vary regionally due to potentially different soil properties of dust source regions (Tegen, 2003). Therefore the net dust radiative forcing (sum of solar and long-wave) exhibits large regional variations, which makes it difficult to estimate a global mean.

The recent development of high-resolution regional climate models (RCMs) offers a useful tool to assess the regional impacts of aerosols, including mineral dust (e.g. Zakey et al., 2006; Perez et al., 2006; Heinold et al., 2007). Compared to General Circulation Models (GCMs), the relatively high-resolution and detailed physical parameterizations of RCMs are particularly suitable to describe the complexity of aerosol processes (Solmon et al., 2006). Furthermore, the results from regional models are well suited for comparison with measurements of individual events at selected sites.

In an effort to improve the understanding of mineral dust impacts on regional climate, Zakey et al. (2006) recently developed a radiatively active desert dust module and coupled it to the regional climate model RegCM3 (Version 3.1, Pal et al., 2007), developed at the Abdus Salam International Centre for Theoretical Physics (ICTP) of Trieste (Italy). The dust module, which includes emission, transport, gravitational settling, wet and dry removal and calculations of dust optical properties, has further been improved by Konare et al. (2008) and Zhang et al. (2009) by including the radiative feedback associated with Sahara dust and the long-wave radiative forcing, respectively. Heinold et al. (2007) also developed a new regional model system (LM-MUSCAT) to estimate the dust direct and semi-direct forcing by means of an online feedback of dust on the model radiation scheme. In addition, Perez et al. (2006) demonstrated the impact of dustradiation interaction on weather forecast improvements by using the Dust REgional Atmospheric Modeling (DREAM) system.

In this paper, RegCM3 is coupled with a radiatively active aerosol model with online feedback on the radiation scheme (Zakey et al., 2006, Konare et al., 2008; Todd et al., 2008; Zhang et al., 2009), and for the first time, it is used to investigate the aerosol radiative forcing (at solar and thermal wavelengths) and related climate effects during African dust in- trusions over the Central Mediterranean. Note that the inclusion of the aerosol feedback both at solar and thermal wavelengths can lead to a decrease of the bias between modeled and observation-based atmospheric parameters. RegCM3 is used in this study to simulate the test period of July 2003, which includes two significant episodes of mineral dust intrusions from the Sahara onto the Central Mediterranean on 17 and 24 July, 2003 (Tafuro et al., 2006). The RegCM3 aerosol module includes, in addition to dust particles, sulphates, hydrophobic and hydrophilic black carbon and organic carbon (Solmon et al., 2006; Zakey et al., 2006). Note that compared to the work of Zhang et al. (2009) that is related to the simulation of dust aerosol over East Asia, our simulations also include anthropogenic aerosols. As mentioned, the Mediterranean basin is characterized by a complex atmospheric chemistry influenced by regional and long-range transported emissions from both continental Europe and the Africa deserts (Santese et al., 2008). Therefore, it is very important to use a model where the contribution of different aerosol components is considered even during dust events. Recent studies at a South-East Italian site (Bellantone et al., 2008) clearly revealed that carbonaceous and sulphate particles were the main components of fine-mode aerosols during dust outbreaks, representing more than $50 \%$ of the total aerosol burden.

The RegCM3/aerosol model performance is tested in this paper with case studies by comparison with a range of observations, including satellite products, sun/sky radiometer measurements, radio sounding measurements, and lidar profiles at selected Central Mediterranean sites. A better understanding of the model behavior can allow improving the parameterization of aerosol processes in order to contribute to the understanding of the aerosol role in the climate system. At present, there exists considerable uncertainty in model estimates of both anthropogenic-aerosol and dust emission. Therefore, the improved parameterization of aerosol processes is an important step in the further development of climate and Earth system models. After a brief model description is given in Sect. 2, the comparison of observations and model data in the reference (REF) experiment is presented in Sect. 3 and the aerosol radiative effect is analyzed in Sect. 4. In addition to the REF simulation, two experiments are analyzed to highlight both the effects of the aerosol online feedback on the radiation scheme (Sect. 5) and the direct and semi-direct radiative effects by dust particles both at solar and thermal wavelengths (Sect. 6). Summary and conclusion are given in Sect. 7.

\section{RegCM3 modeling system}

The Regional Climate Model Version 3 (RegCM3) used in the present work is a hydrostatic, sigma vertical coordinate model based on the mesoscale model MM5 (Grell et al., 1994), with improvements in various physics packages 
(Pal et al., 2007). Typical horizontal grid spacings for climate applications range from 20 to $80 \mathrm{~km}$. Atmospheric radiative transfer processes at solar (SW) and thermal (LW) wavelengths are from the NCAR global model CCM3 and are described by Kiehl et al. (1996). Land surface processes, which describe the transfer of energy, mass and momentum between the atmosphere and the biosphere, are represented via the Biosphere-Atmosphere Transfer Scheme (BATS1e; Dickinson et al., 1993). Planetary boundary layer computations follow the non-local parameterization of Holtslag et al. (1990). The mass flux scheme of Grell (1993) is used to describe convective precipitation and the sub-grid explicit moisture scheme of Pal et al. (2000) is used to represent nonconvective precipitation.

\subsection{Anthropogenic aerosol model}

The anthropogenic aerosol model implemented within RegCM3 includes prognostic equations for six tracers: the $\mathrm{SO}_{2} / \mathrm{SO}_{4}^{2-}$ system, hydrophobic and hydrophilic black carbon (BC) and organic carbon (OC). Solmon et al. (2006) presents a detailed description of this scheme along with the emission inventories used by the model. Solmon et al. (2006) evaluated the model performance in terms of surface concentrations and aerosol optical depth over a wide and contrasted domain extending from Northern Europe to southern sub-tropical Africa at a $60 \mathrm{~km}$ spatial grid spacing without considering the aerosol radiative forcing.

\subsection{Dust model}

The desert dust module implemented within RegCM3 is described in detail by Zakey et al. (2006). It is based on the works of Marticorena and Bergametti (1995) and Alfaro and Gomes (2001) and includes emission, transport, gravitational settling, wet and dry removal, and calculation of dust optical properties. The coupled RegCM3-dust model, without the online feedback of dust on the model radiation scheme, was tested by Zakey et al. (2006) by simulating a Northeastern Africa dust outbreak and a West Africa-Atlantic dust outbreak, as well as by performing a three month simulation over an extended domain covering the Africa-Europe sector. Comparisons with observations gave encouraging indications concerning the use of the dust model for climate applications.

The coupled RegCM3-dust model was then used by Konare et al. (2008) to investigate the effect of the shortwave radiative forcing of Saharan dust on the West Africa monsoon. It was shown that the short-wave forcing was dominant in generating a reduction of monsoon northward penetration and precipitation over the Sahel. More recently, as we have previously mentioned, the coupled RegCM3-dust model was further implemented by Zhang et al. (2009) to simulate over East Asia the net radiative forcing (short-wave and long-wave) and related climate effects of dust aerosols.
The dust module has a size spectrum from 0.01 to $20.0 \mu \mathrm{m}$, which is divided into 4 size-bins, each covering part of the whole spectrum of particle diameter: i.e. the fine $(0.01-$ $1.0 \mu \mathrm{m})$, accumulation $(1.0-2.5 \mu \mathrm{m})$, coarse $(2.5-5.0 \mu \mathrm{m})$, and giant $(5.0-20.0 \mu \mathrm{m})$ particle mode. The evolution of each bin is described by a prognostic equation for the dry size of the dust particle (Zakey et al., 2006; Solmon et al., 2006).

The radiative code in the RegCM3 employs the $\delta$ Eddington approximation for radiative flux calculations, and the wavelength spectrum is divided into 18 discrete intervals from 0.2 to $4.5 \mu \mathrm{m}$. Seven of these span the ultraviolet $(0.2-$ $0.35 \mu \mathrm{m})$, one covers the visible $(0.35-0.64 \mu \mathrm{m})$ and the remaining bands cover the infrared or special absorption windows. Zhang et al. (2009) provide a detailed description of the aerosol parameters used to perform radiative forcing calculations.

The dust SW radiative effect is calculated using asymmetry factor, single scattering albedo, and mass extinction coefficient obtained from Mie calculations. The refractive indices of mineral dust aerosols for the relevant SW spectral windows are taken from the OPAC database (Hess et al., 1998).

In the LW domain, dust effects are accounted for by introducing the dust emissivity (and hence absorptivity) according to the parameterization of Kiehle et al. (1996). The dust LW emissivity is calculated according to:

$\varepsilon_{\mathrm{LW}}(z)=1-e^{-D k_{\mathrm{lwabs}} b(z)}$

where $D=1.66$ is a diffusivity factor, $b(\mathrm{z})$ is the dust burden $\left(\mathrm{gm}^{-2}\right)$ of a given layer and $k_{\text {lwabs }}\left(\mathrm{m}^{2} \mathrm{~g}^{-1}\right)$ is the mass absorption coefficient calculated using Mie theory for the relevant LW spectral windows, for each size bin and using LW refractive indices consistent with Wang et al. (2006).

The OPAC dataset allows the calculation of dust optical properties at 61 wavelengths between 0.25 and $40 \mu \mathrm{m}$, providing the real and imaginary parts of the refractive indices for each wavelength range. In our study we use the wavelength range from 0.2 to $4.5 \mu \mathrm{m}$. Figure 1 shows (a) single scattering albedo and (b) asymmetry factor versus wavelength retrieved from Mie calculations for the four size bins. The plots of Fig. 1a and b are in satisfactory accordance with the corresponding ones by OPAC dataset and with AERONET data (e.g. Bergamo et al., 2008).

\subsection{Experiment design}

The model domain used in this study covers major parts of the Sahara desert and Southern Europe with $100 \times 115$ grid points at a horizontal grid spacing of $50 \mathrm{~km}$, with 18 vertical sigma layers and model top at $100 \mathrm{hPa}$. It is worth noting that the grid spacing of $50 \mathrm{~km}$ used in this test study is not much higher than the ones used by some GCMs with an aerosol module. Nevertheless, we believe that the selected grid spacing does not represent a limiting factor of the paper's main scope. However, our modeling system can operate at smaller grid spacing. Figure 1c shows the model domain in addition 

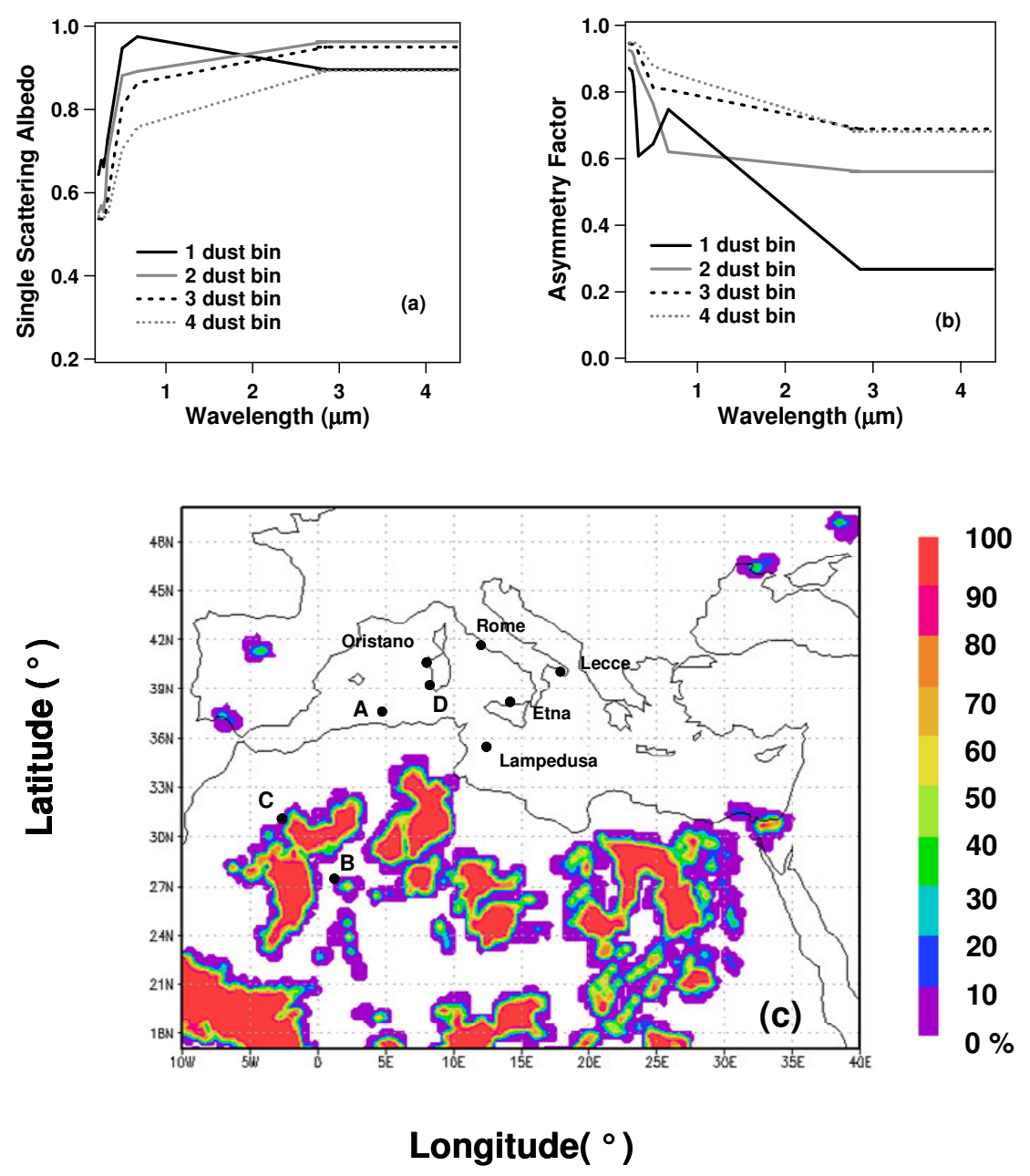

Fig. 1. (a) Single scattering albedo and (b) asymmetry factor versus wavelength retrieved from Mie calculations for the four size bins. (c) Sand source percentages inside the model domain. Full dots indicate the location of some Italian AERONET sites and of site A. B, C, and D indicate the the geographical location of In Salah, Bechar, and Cagliari, respectively.

to sand source percentages (color coded plot) to indicate the location of main dust sources over the model domain. Meteorological initial and time-evolving lateral boundary conditions for the RegCM3 simulations are from the National Centers for Environmental Prediction/National Center for Atmospheric Research (NECP/NCAR) re-analysis (Kalnay et al., 1996). The land cover is specified using the Global Land Cover Characterization (GLCC) Version 2 data provided by the US Geology Survey (USGS) Earth Resources Observation System Data Center (Loveland et al., 2000). Soil texture data are based on the USDA texture classification (USDA, 1999). The model time step is of six hours.

The model simulations extend from 1 to 31 July 2003 in order to capture the main African dust intrusions that occurred over the Mediterranean basin during July 2003. These have been well documented for example by Tafuro et al. (2006). Three simulations are conducted and analyzed. The radiatively active aerosol model with online feedback on the RegCM3 radiation scheme is used for the reference
(REF) simulation. The second simulation (Exp1) includes the radiatively active aerosol model, but the online feedback on the RegCM3 radiation is not accounted for. Finally, in order to examine the contribution of the mineral dust radiative forcing a simulation not accounting for the mineral aerosol component is performed (Exp2).

\section{Model validation}

Model results are validated at selected Central Mediterranean sites, by comparison with aerosol optical depths (AODs) from satellites and sun/sky radiometer measurements, with extinction coefficient vertical profiles obtained from lidar measurements, and with radio sounding temperature measurements. The evaluation of individual dust events is a necessary step in order to assess the realism of emission and transport processes in numerical models. 

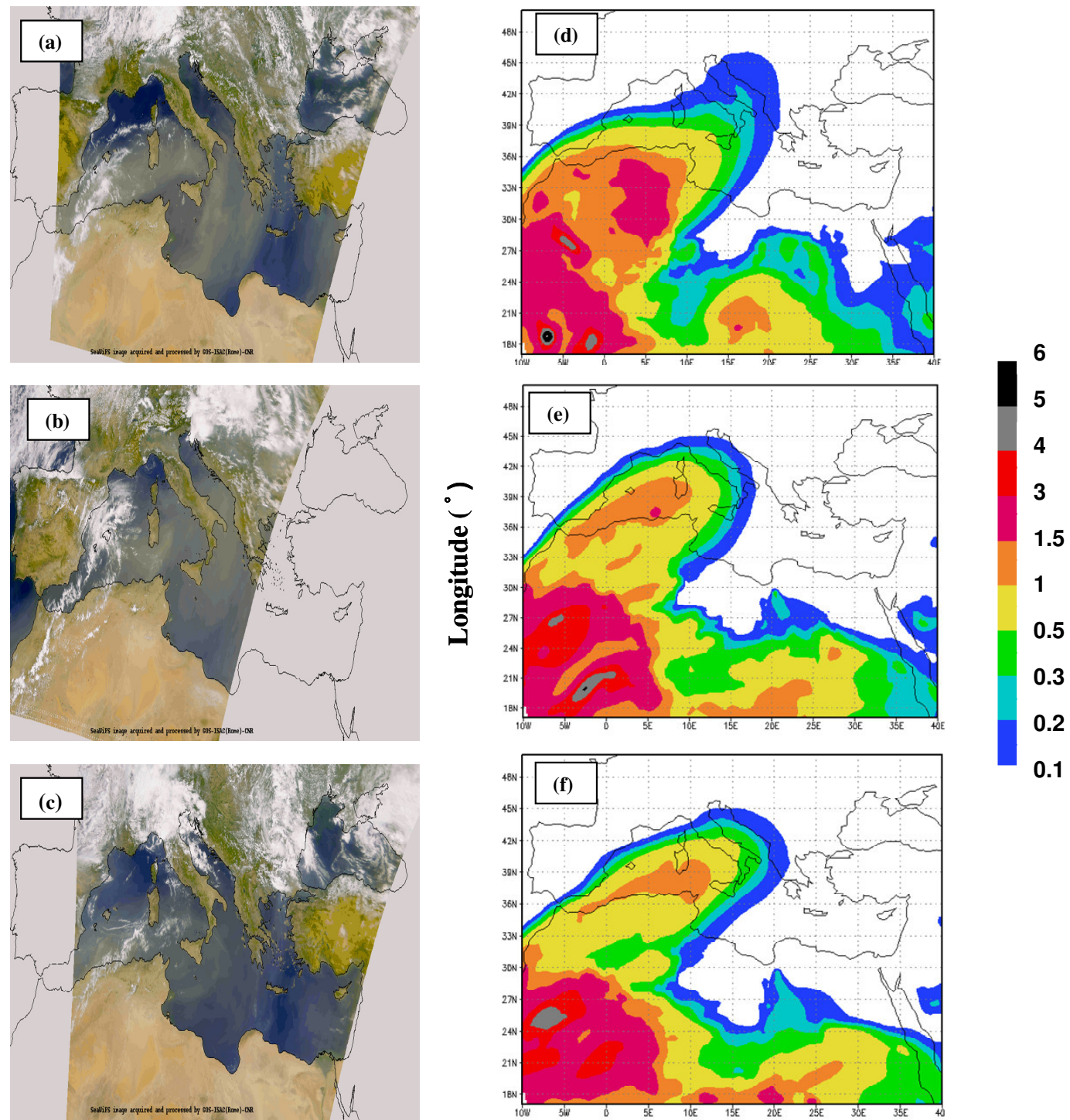

Latitude ( $\left.{ }^{o}\right)$

Fig. 2. (a-c) SeaWiFS true color images and (d-f) color-coded plots of simulated AODs (daily average) at the $350-640 \mathrm{~nm}$ model band for 17,23 , and 24 July 2003, respectively.

\subsection{Overview of July $\mathbf{2 0 0 3}$ african dust intrusion episodes}

Particularly intense sand storms occurred over Northwestern Africa on 17 July, and 23-24 July, 2003, as revealed by the true-color images from the Sea Wide Field-of-view Sensor (SeaWiFS, http://www.nrlmry.navy.mil/aerosol/) on board of the NASA SeaStar spacecraft (Fig. 2a-c). One picture per day is shown in Fig. $2 \mathrm{a}-\mathrm{c}$ for the whole Mediterranean region as a composite of the data collected between 11:00 and 13:00 UTC along the spacecraft polar orbit (Tafuro et al., 2006). Figure 2 shows that the dust intrusion from the Western Sahara extends all the way to the Italian peninsula and Western Greece. Figure 3 presents a comparison between the simulated daily mean wind fields at $10 \mathrm{~m}$ (ac) and the corresponding NCEP-NNRP2 reanalysis dataset used for the model initial and lateral boundary conditions interpolated onto the model grid for 17, 23 and 24 July, respectively. The wind patterns are well captured by RegCM3. Daily mean values of dust emission fluxes $\left(\mu \mathrm{g} \mathrm{m}^{-2} \mathrm{~s}^{-1}\right)$ are reported in Fig. 3g-i by color coded plots for 17, 23 and 24 July, respectively. We observe that Western Sahara is the main dust source on 17 July, even if significant dust sources also are activated over Mauritania and Algeria. Intense dust emissions are especially activated over the Mauritania/Mali/Algeria border on 23 and 24 July. 

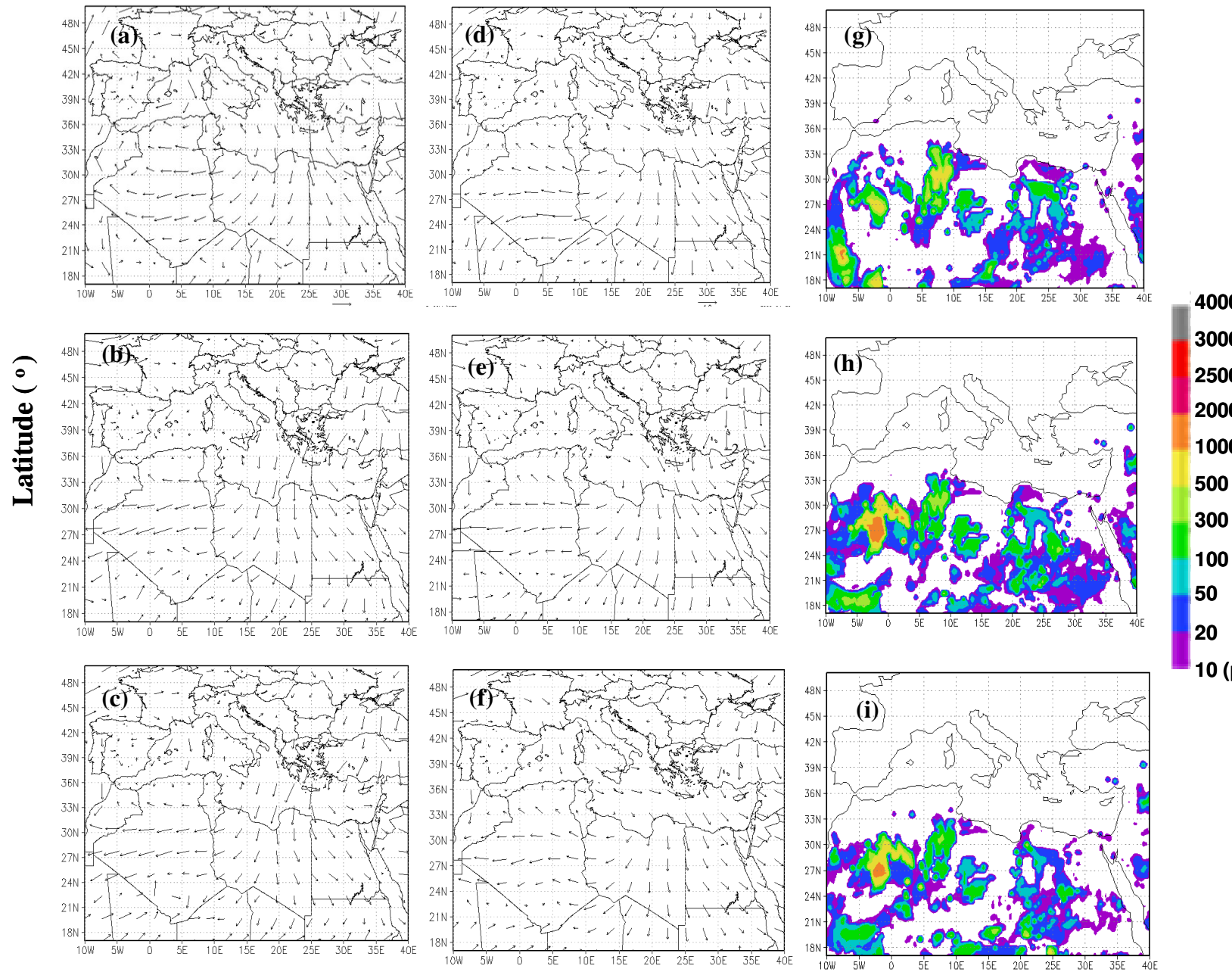

$10\left(\mu \mathrm{g} \mathrm{m}-^{-2} \mathrm{~s}^{-1}\right)$

\section{Longitude ( $\left.{ }^{\circ}\right)$}

Fig. 3. Comparison between (a-c) RegCM3 simulated 10-m winds and (d-f) NCEP-NNRP2 reanalysis for 17, 23 and 24 July, respectively. Daily mean values of dust emission fluxes $\left(\mu \mathrm{g} \mathrm{m}^{-2} \mathrm{~s}^{-1}\right)$ are shown in (g-i) by color coded plots for 17, 23 and 24 July 2003 , respectively.

\subsection{Comparison of simulated and observed aerosol optical depths}

Figure $2 \mathrm{~d}-\mathrm{f}$ show by color coded plots the simulated (daily average) total aerosol optical depth (AOD) at the model band 350-640 nm for 17, 23 and 24 July, respectively. Comparison with Fig. 2a-c reveals that RegCM3 catches the spatial distribution of the dust intrusions over the Central Mediterranean. The AOD reaches values of up to 6 over the dust source regions (Fig. 2d-e) and decreases to values of up to 1.5 over the Central Mediterranean and the Italian Peninsula.

Daily AOD-mean-values from the model (dashed black lines) are compared in Fig. 4a-e to corresponding daily AOD (solid black lines) retrieved from cloud-screened and quality-assured AERONET sun/sky photometer measurements. More specifically, AOD daily-mean-values at $550 \mathrm{~nm}$ retrieved from sun/sky photometer measurements at Lampedusa $\left(35.52^{\circ} \mathrm{N}, 12.63^{\circ} \mathrm{E}\right)$, Oristano $\left(39.91^{\circ} \mathrm{N}, 8.5^{\circ} \mathrm{E}\right)$, Etna $\left(37.61^{\circ} \mathrm{N}, 15.02^{\circ} \mathrm{E}\right)$, Lecce $\left(40.33^{\circ} \mathrm{N}, 18.10^{\circ} \mathrm{E}\right)$, and Rome $\left(41.84^{\circ} \mathrm{N}, 12.65^{\circ} \mathrm{E}\right)$ are plotted in Fig. 4a-e. These Italian AERONET sites (Fig. 1c) have been significantly affected by dust outbreaks in July 2003, as clearly seen in Fig. 2 . It is also worth mentioning that we use AERONET daily-meanvalues of the Angstrom coefficient $(440 \mathrm{~nm} / 870 \mathrm{~nm})$ and the $\mathrm{AOD}$ at $440 \mathrm{~nm}$ to estimate AODs at $550 \mathrm{~nm}$. The uncertainty on AERONET AODs is \pm 0.01 and is assumed wavelengthindependent (Dubovik et al., 2000). Daily-mean-values of the Angstrom coefficient $(\AA)$ that are plotted in Fig. 4a-e by grey dotted lines also indicate that AOD peak values are due to dust intrusion events. A mainly depends on the aerosol size distribution and several studies have revealed that $\AA$ appears as a good marker to trace the temporal evolution of 

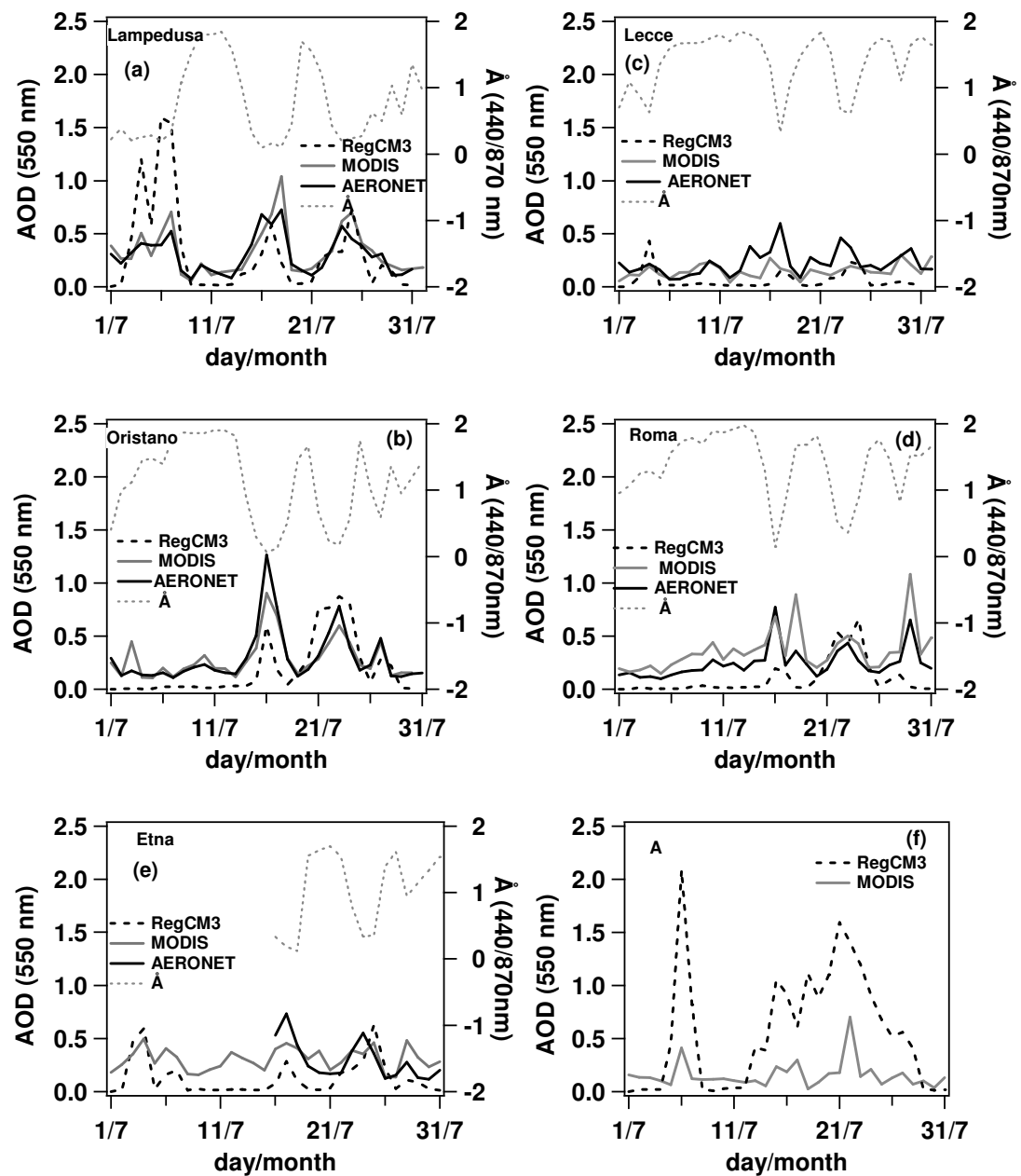

Fig. 4. AOD daily-mean-values for July 2003 from the model (black dashed line), AERONET sun/sky radiometer measurements (black solid line), and MODIS satellite measurements (grey solid line), and daily-mean-values of the Angstrom coefficient (grey dotted line) at (a) Lampedusa, (b) Oristano, (c) Lecce, (d) Rome, and (e) Etna. (f) AOD daily mean values from the model (black dashed line) and from MODIS (grey solid line) at site $\mathrm{A}\left(37.60^{\circ} \mathrm{N}, 5.00^{\circ} \mathrm{E}\right)$.

dust outbreaks (e.g. Tafuro et al., 2006). Typical values range from $\AA>2$ for fresh smoke particles, which are dominated by accumulation mode aerosol, to nearly zero for large dust particles (Dubovik et al., 2000).

Figure 4 shows a good performance of the model in catching the AOD evolution with time at most sites. The events on 17, 23, and 24 July are captured at Lampedusa, Oristano, Roma and Etna. The AOD is generally underestimated at Lecce, the location farthest away from the dust source regions, suggesting a somewhat weak long range transport by the model. In fact, we observe from Fig. 4 that the differences between model- and observation-based-AODs increase with the distance of the AERONET site from the North-West Africa coast. This result is further illustrated by Fig. 5a and $b$ which show the scatterplot of RegCM3 AODs versus AERONET AODs retrieved (a) at Lampedusa (full dots) and Oristano (open triangles) and (b) at Lecce (rombs), Etna (crosses), and Rome (boxes). The solid black lines in the figures represent the linear regression line fitting the data points. Regression line slope and linear correlation coefficient $(R)$ are also given for each plot in addition to the root mean square (RMS) difference between RegCM3 AODs and the corresponding daily AERONET AODs. We observe from Fig. 5a that the regression line slope is $0.8 \pm 0.1$ and that $R=0.5$ at the stations Lampedusa and Oristano closer to the dust source region. Conversely, the regression line slope in Fig. $5 b$ is significantly lower $(0.36 \pm 0.05)$ and the data are less correlated $(R=0.35)$ at the stations farther away. These results indicate that on average RegCM3 underestimates AODs and that this underestimation increases with the distance from the dust sources. 

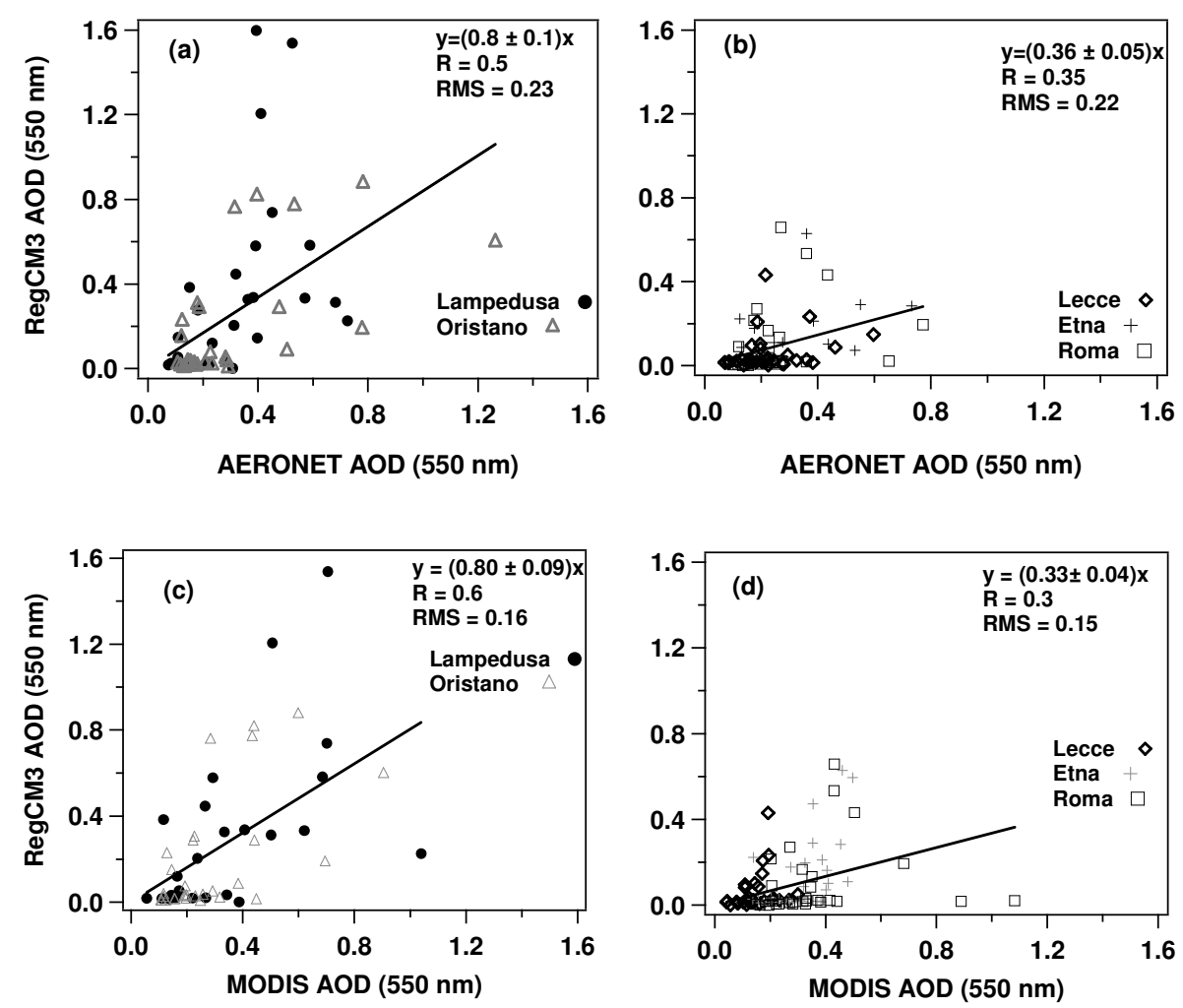

Fig. 5. Scatterplot of RegCM3-AODs versus AERONET-AODs retrieved (a) at Lampedusa (full dots) and Oristano (open triangles) and (b) at Lecce (rombs), Etna (crosses), and Rome (boxes). Scatterplot of RegCM3-AODs versus MODIS-AODs retrieved (c) at Lampedusa (full dots) and Oristano (open triangles) and (d) at Etna (crosses), Lecce (rombs), and Rome (boxes). The solid black line represents in each plot the linear regression line fitting the data points. Regression line slope and linear correlation coefficient $(R)$ are also given in each plot in addition to the root mean square (RMS) difference.

The AOD daily mean values retrieved by measurements of the Moderate Resolution Imaging Spectroradiometer (MODIS), onboard of both the EOS Terra and Aqua polarorbiting satellites (King et al., 1992) are also shown in Fig. 4a-f (grey solid line). In particular, MODIS Land_Ocean AODs at $550 \mathrm{~nm}$ calculated by averaging all data points of a $50 \times 50 \mathrm{~km}^{2}$ box centered at the AERONET site are plotted in Fig. 4a-e. The consistency of MODIS AODs with AERONET AODs is quite satisfactory, even if the AERONET AODs are retrieved from local measurements. Figure 5c-d shows the scatterplot of RegCM3 AODs versus MODIS AODs retrieved (c) at Lampedusa (full dots) and Oristano (open triangles) and (d) at Etna (crosses), Lecce (rombs), and Rome (boxes). Again, the solid black line represents the linear regression fitting the data points. Figure $5 \mathrm{c}$ shows that the regression line slope of the LampedusaOristano scatterplot is $0.80 \pm 0.09$, while the regression line slope in Fig. $5 \mathrm{~d}$ is $0.33 \pm 0.04$. In addition, the data points of Fig. $5 \mathrm{~d}$ are less correlated than those of Fig. $5 \mathrm{c}$. These results thus generally confirm the findings based on the AERONET observations. Figure $4 \mathrm{f}$ shows AOD daily mean values from the model (black dashed line) and from MODIS (grey solid line) retrieved $\sim 87 \mathrm{~km}$ away from the Africa coast (site A).
The site A location $\left(37.60^{\circ} \mathrm{N}, 5.00^{\circ} \mathrm{E}\right)$ is shown in Fig. 1c. MODIS AODs at $550 \mathrm{~nm}$ have been calculated by averaging all data points of a $50 \times 50 \mathrm{~km}^{2}$ box centered at site A. Figure $4 \mathrm{f}$ also shows the good model performance in catching the AOD evolution with time but, peak values of modelAODs are significantly larger than peak values of MODISAODs. This last result showing that the model overestimates AODs at sites closest to dust sources, are consistent with previous findings.

In comparing simulated and observed AODs, it should be stresses that a contribution to the differences between simulated and observed AODs is due to the fact that both the AERONET- and MODIS-AODs are representative of the total aerosol load, while the RegCM3 model only includes few aerosol components (sulfate, black carbon, organic carbon, and dust). The underestimate of sulfate and carbon particle concentrations representing the main anthropogenic aerosol components of local origin and/or long-range transported from industrialized areas (e.g. Bellantone et al., 2008; Santese et al., 2008) may also be responsible for the underestimation of AODs mainly at sites far away from dust sources. In this respect, it is worth noting from Fig. 4 that AODs larger than 0.05 were found at all AERONET sites on 

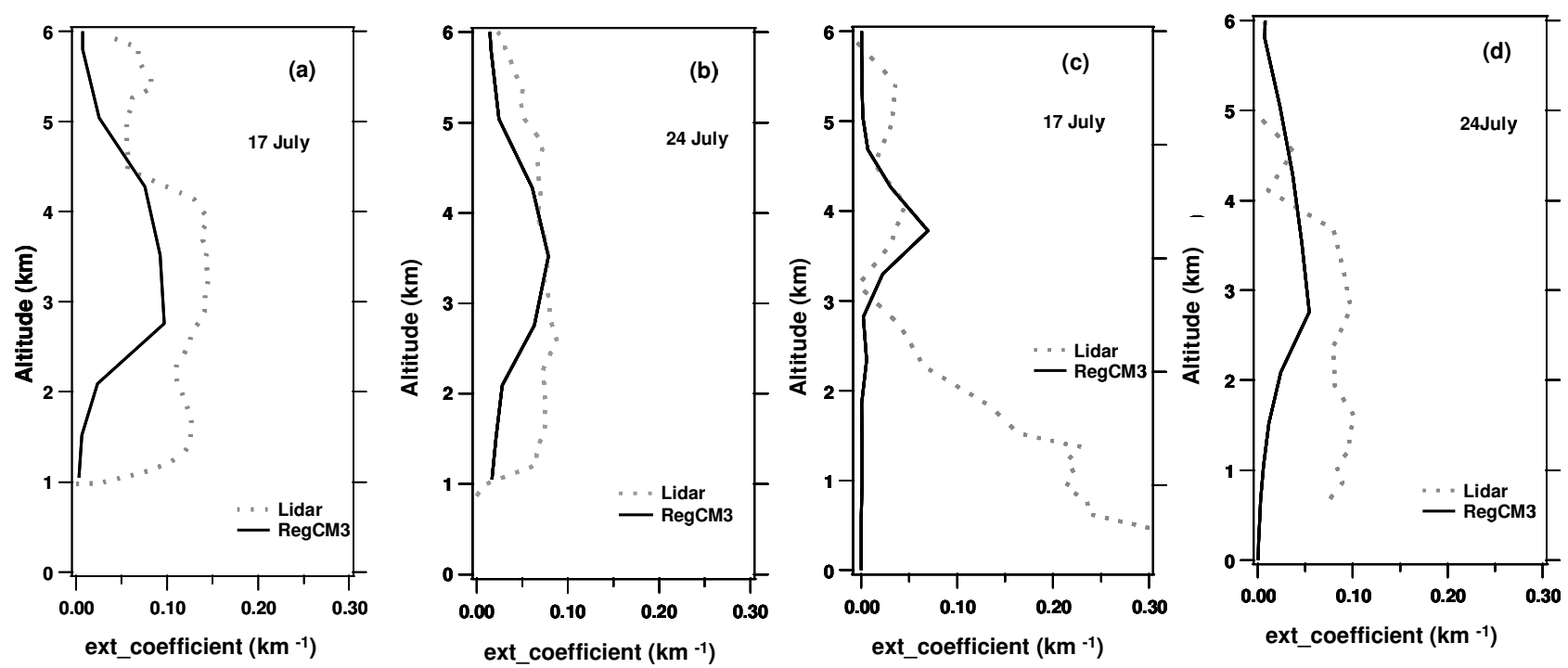

Fig. 6. Extinction coefficient profiles by RegCM3 (black line) and lidar measurements (grey dotted lines) at Etna on (a) 17 and (b) 24 July and at Lecce on (c) 17 and (d) 24 July. In particular, the extinction coefficient profile retrieved at Etna by lidar measurements performed on 17 July from 14:05 to 14:15 UTC is compared in Fig. 6a to the RegCM3 extinction coefficient profile at 12:00 UTC. While, the 24 July extinction coefficient profile retrieved by lidar measurements from 19:30 to 19:40 UTC is compared in Fig. 6b with the one by RegCM3 at 18:00 UTC. Lecce's extinction coefficient profiles have been retrieved by lidar measurements (grey dotted lines) from 13:00 to 14:00 UTC (c) on 17 July and from 20:00 to 21:00 UTC (d) on 24 July. Black lines show the extinction coefficient profiles by RegCM3 at (c) 12:00 and (d) 18:00 UTC, respectively.
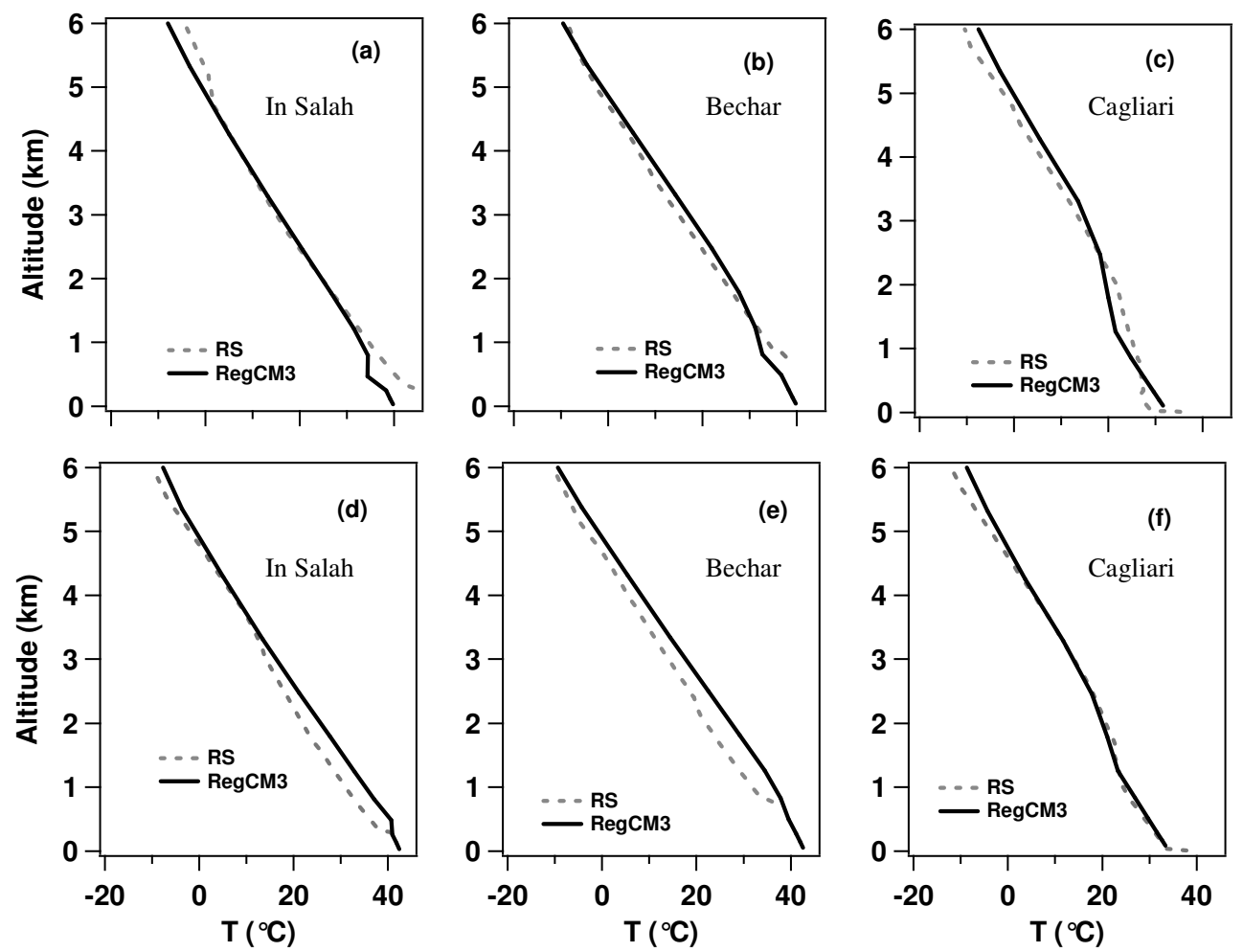

Fig. 7. Instantaneous (12:00 UTC) temperature vertical profiles by RegCM3 (black solid line) and radio sounding measurements (grey dashed lines) at In Salah, Bechar, and Cagliari, respectively, on (a-c) 17 and (d-f) 24 July 2003. 
dust-free days, when the simulated AODs were very small. The uncertainties on dust optical properties that depend on the particle size and refractive indices (Zhang et al., 2009) may also contribute to the differences between RegCM3- and observation-based-AODs. To this end, work is on progress to investigate if simulated particle sizes and refractive indices can help to explain the overestimation/underestimation of the dust load after transport.

\subsection{Comparison of simulated and measurement-based vertical profiles of aerosol and temperature}

Aerosol extinction coefficient profiles by lidar measurements at Etna and Lecce are compared to corresponding profiles provided by RegCM3 in Fig. 6a-d, respectively. An elastic-Raman lidar employing a $\mathrm{XeF}$ excimer laser has routinely been used during 2003 at the Physics Department of Salento's University, at the suburbs of Lecce, for monitoring aerosol vertical profiles. In particular, Lecce's lidar allows the retrieval of vertical profiles of the aerosol extinction coefficient $\alpha_{\text {ext }}$ at $351 \mathrm{~nm}$ (De Tomasi and Perrone, 2003). At Mount Etna, a vehicle-mounted lidar system (VELIS, Gobbi, 2000) that employs a Nd:YAG laser has operated from 15 to 31 July, 2003. The VELIS lidar allows the retrieval of extinction coefficient vertical profiles at $532 \mathrm{~nm}$ (Tafuro et al., 2006).

Figure 6 shows examples of vertical profiles of extinction coefficients on 17 and 24 July at the two locations as observed by lidar and as simulated at the closest model grid point and time. In Fig. 6c-d lidar profiles at $550 \mathrm{~nm}$ are plotted using Angstrom coefficient values retrieved by sun/sky photometer measurements. Relative uncertainties on lidar extinction profiles vary in the range of 5-30\%.

Given all the uncertainties underlying the comparison of grid point modeled data and station profiles, the agreement with observations at the Etna site is satisfactory. Conversely, at Lecce significantly larger extinction coefficients are found in the lidar data, primarily below $3 \mathrm{~km}$ of altitude. The high variability within few hours of the aerosol vertical distribution during Sahara dust outbreaks (e.g. Tafuro et al., 2007), may partially account for the differences between experimental and simulated extinction profiles. However, the extinction coefficient underestimation at Lecce is consistent with the AOD data of Figs. 4 and 5. Thus, the larger extinction coefficients retrieved at Lecce by lidar measurements may also be an indication of weak long range transport of dust. Note that dust particles affect all the aerosol column few hours after the onset of the dust event, in accordance with lidar measurements, (e.g. Pavese et al., 2008). The underestimate of the anthropogenic aerosol amount also may represent a contributing factor: morphological and elemental analyses on particulate matter samples collected at Lecce show that the anthropogenic fine mode aerosol, mainly composed of nitrate, sulfate, and carbon particles, can represent more than $50 \%$ of the aerosol load even during dust outbreaks (Bellantone et al., 2008).

Radio sounding measurements of temperature $(T)$ performed at selected meteorological stations (http://esrl.noaa. gov/raobs/) are compared to corresponding REF-simulation profiles to further test the model performance. Figure 7 shows as an example temperature vertical profiles by the model (black line) and by radio sounding measurements (grey dashed line) at In Salah $\left(27.20^{\circ} \mathrm{N}, 2.47^{\circ} \mathrm{E}\right)$, Bechar $\left(31.62^{\circ} \mathrm{N}, 2.23^{\circ} \mathrm{W}\right)$, and Cagliari $\left(39.25^{\circ} \mathrm{N}, 9.05^{\circ} \mathrm{E}\right)$ meteorological stations for $(\mathrm{a}-\mathrm{c}) 17$ and $(\mathrm{d}-\mathrm{f}) 24$ July, respectively. The accordance between modeled and measured temperature profiles is satisfactory at all sites. The geographical location of In Salah, Bechar, and Cagliari is indicated in Fig. 1c by the letter B, C, and D, respectively.

\section{Aerosol radiative effect during dust outbreaks: reference simulation}

In this section we analyze the short-wave (SW), long-wave (LW), and net aerosol radiative forcing over the model domain during the simulated dust intrusion events. According to IPCC-2007, the level of scientific understanding of the aerosol forcing is medium-low (http://ipcc-wg1.ucar.edu/ wg1/wg1_home.html) and a great effort has been dedicated to improve its estimates through dedicated measurement campaigns and integrated analyses (e.g. Yu et al., 2006). The aerosol forcing depends on several parameters such as surface albedo, aerosol layer altitude, aerosol particle median diameter, and aerosol optical thickness. The sign of the radiative forcing is mainly determined by the value of the aerosol single scattering albedo, which is an uncertain parameter in current aerosol radiation models (Helmert et al., 2007). Dust aerosols are large in size and have absorbing properties in the infrared spectral region. Hence, unlike other aerosol species, they also influence the long-wave radiation. Here we specifically analyze results for the dust events of 17 and 24 July, when a large amount of dust entered the Mediterranean basin (Fig. 4). 17-July daily-mean-values of the SW, LW, and net aerosol forcing at the top of the atmosphere (ToA) and at the surface (sfc) are shown in Fig. 8a-f, respectively, while corresponding values for 24 July are shown in Fig. 9a-f.

Figures $8 \mathrm{a}$ and $9 \mathrm{a}$ show that daily mean values of the direct SW-ToA aerosol forcing are on average positive over dustsources. In particular, the SW-ToA aerosol forcing reaches values up to $50 \mathrm{Wm}^{-2}$ at the sites where daily mean values of dust emission fluxes $\left(\mu \mathrm{g} \mathrm{m}^{-2} \mathrm{~s}^{-1}\right)$ are highest. Conversely, the SW-ToA aerosol forcing is on average negative over the Mediterranean areas affected by the dust intrusion. This change in sign of the SW-ToA aerosol forcing is related to the dependence of mineral aerosol radiative effects on the 

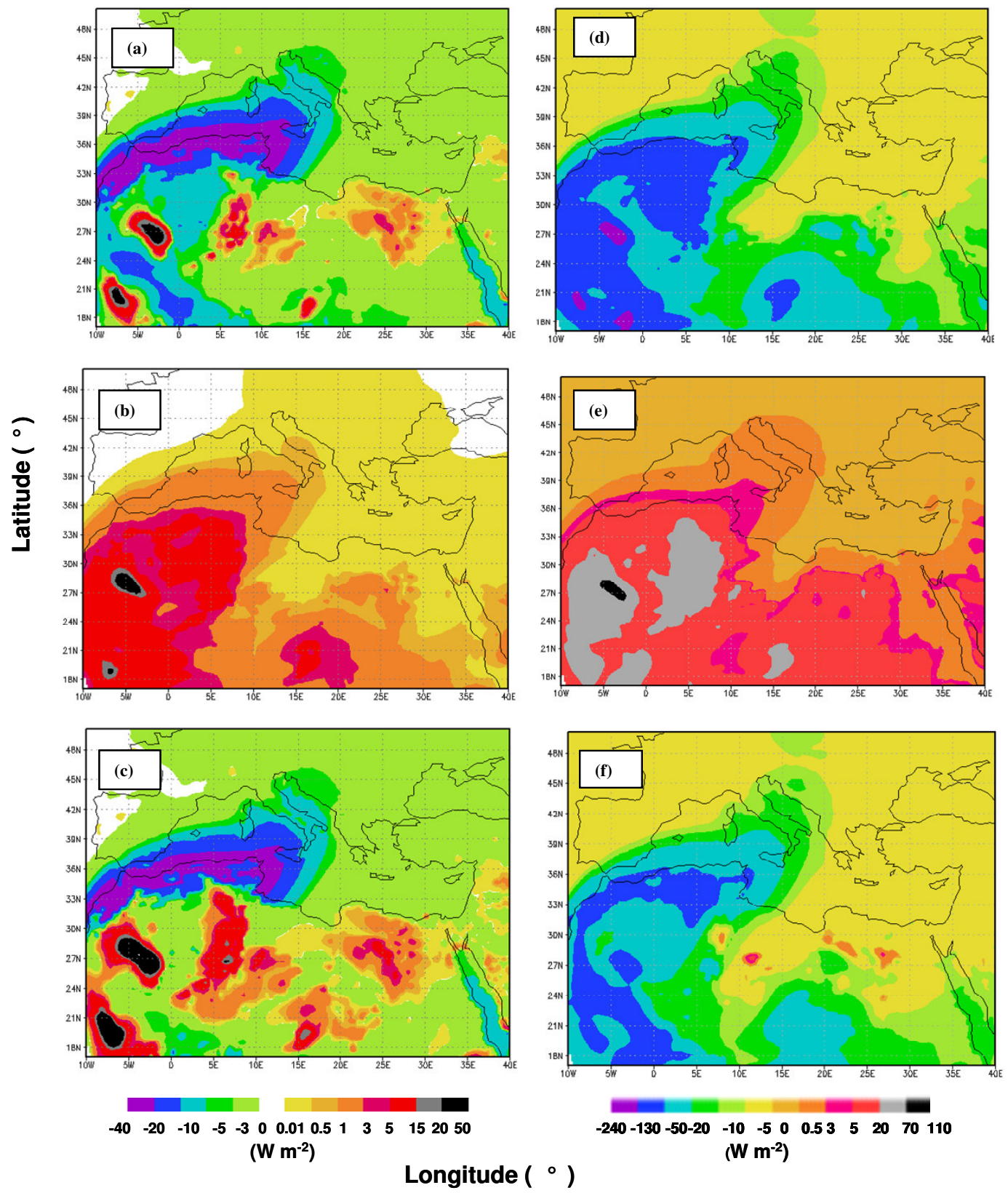

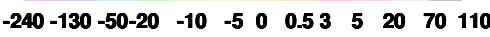
( $W \mathrm{~m}^{-2}$ )

Fig. 8. 17 July 2003 daily mean values of the $\mathrm{SW}$ direct aerosol forcing $\left(\mathrm{Wm}^{-2}\right)$ at the (a) ToA and (d) surface, of the LW direct aerosol forcing $\left(\mathrm{Wm}^{-2}\right)$ at the (b) ToA and (e) surface, and of the net direct aerosol forcing $\left(\mathrm{Wm}^{-2}\right)$ at the (c) ToA and (f) surface for the REFexperiment.

brightness of the underlying surface (e.g. Balkanski et al., 2007). Over bare surfaces with a high surface albedo $(>0.3)$, such as the Sahara desert, the mineral aerosol tends to warm the atmospheric column by providing a less reflecting layer. Conversely, over dark surfaces, such as ocean and deciduous forests, where the surface albedo is less than 0.15 , the effect of the mineral dust is similar to that of sulphates and lead to cooling of the atmospheric column. Therefore, our results show that the cooling effect by aerosol at the ToA is larger over Europe than over the Sahara: the daily SW-ToA aerosol forcing averaged over Europe and the Mediterranean Sea is -3.9 and $-4.9 \mathrm{Wm}^{-2}$ on 17 and 24 July, respectively (Table 1). Conversely, the daily SW-ToA aerosol forcing averaged over the Sahara is -3.0 and $-2.6 \mathrm{Wm}^{-2}$ on 17 and 24 July, respectively (Table 1).

Daily mean values of the SW-sfc aerosol forcing are always negative (Figs. 8d and 9d), reaching values of up to $-240 \mathrm{Wm}^{-2}$ at the sites where daily mean values of AODs are highest (Figs. 2 and 3). In particular, the daily SW-sfc aerosol forcing averaged over Europe and the 

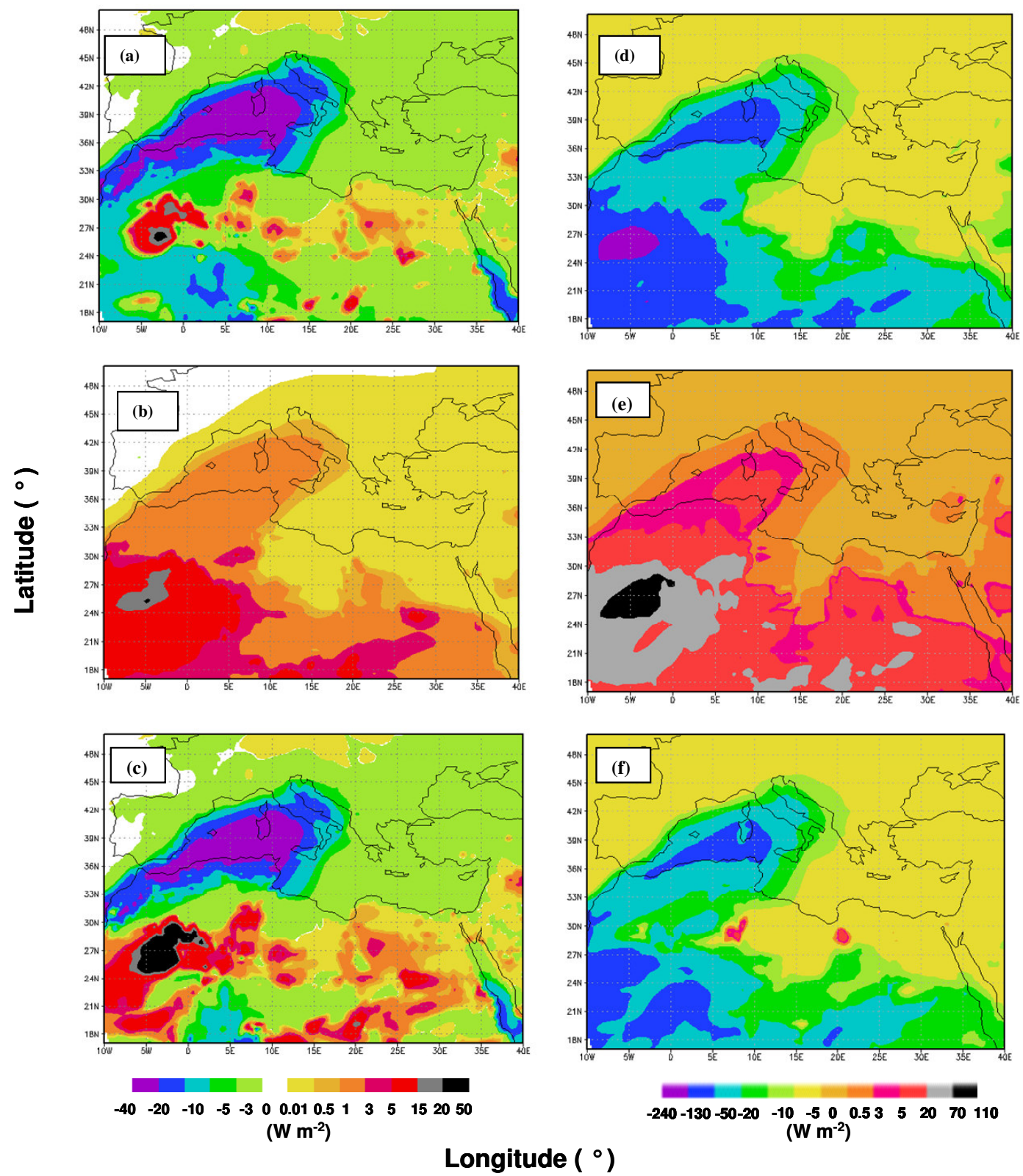

Fig. 9. 24 July 2003 daily mean values of the $\mathrm{SW}$ direct aerosol forcing $\left(\mathrm{Wm}^{-2}\right)$ at the (a) ToA and (d) surface, of the LW direct aerosol forcing $\left(\mathrm{Wm}^{-2}\right)$ at the (b) ToA and (e) surface, and of the net direct aerosol forcing $\left(\mathrm{Wm}^{-2}\right)$ at the (c) ToA and (f) surface for the REFexperiment.

Mediterranean Sea is -8 and $-10 \mathrm{Wm}^{-2}$ on 17 and 24 July, respectively (Table 1), while averaged over Sahara it is -33 and $-35 \mathrm{Wm}^{-2}$ on 17 and 24 July, respectively (Table 1).

The LW aerosol forcing is positive throughout the domain (Figs. 8 and 9) and over Africa daily values vary up to 110 and $50 \mathrm{Wm}^{-2}$ at the surface and ToA, respectively. LW aerosol forcing values are significantly smaller over the Mediterranean. As a consequence, the LW aerosol forcing enhances the ToA radiative forcing over dust sources and offsets the (negative) SW-ToA forcing away from them. Daily values of the LW aerosol forcing averaged both over the whole simulation domain and for the regions below and above $35^{\circ} \mathrm{N}$ are given in Table 1 . We observe from Table 1 that the LW aerosol forcing offsets the SW forcing averaged over Sahara by about $100 \%$ and $36 \%$ at the ToA and surface, respectively on 17 July. Model results also show that the netToA aerosol radiative forcing is positive over Sahara when dust sources are activated and lead to AODs $\geq 0.8$. Under these conditions, the net-ToA aerosol forcing thus enhances the ToA forcing due to greenhouse gases. 
Table 1. REF-simulation: daily-mean values of the short-wave (SW) and long-wave (LW) aerosol forcing at the top of the atmosphere (ToA) and surface (sfc), the SW forcing efficiency (FE) at the ToA and surface, the SW atmospheric forcing (AF), the aerosol optical depth (AOD), the aerosol column burden (CB), the 2 m-temperature $(T)$, and the ground wind speed (WS) averaged over the whole simulation domain (Wh-domain) and over the simulation domain located above $35^{\circ} \mathrm{N}\left(\mathrm{a}-35^{\circ} \mathrm{N}\right)$ and below $35^{\circ} \mathrm{N}\left(\mathrm{b}-35^{\circ} \mathrm{N}\right)$ by the REF-simulation and for 17 and 24 July.

\begin{tabular}{lrrrrrr}
\hline \multirow{2}{*}{ Parameters } & Wh-domain & $\begin{array}{r}17 \text { July } \\
\mathrm{a}-35^{\circ} \mathrm{N}\end{array}$ & $\mathrm{b}-35^{\circ} \mathrm{N}$ & Wh-domain & $\begin{array}{r}24 \text { July } \\
\mathrm{a}-35^{\circ} \mathrm{N}\end{array}$ & $\mathrm{b}-35^{\circ} \mathrm{N}$ \\
\hline & & & & & & \\
SW-ToA $\left(\mathrm{Wm}^{-2}\right)$ & -3.4 & -3.9 & -3.0 & -3.5 & -4.9 & -2.6 \\
SW-sfc $\left(\mathrm{Wm}^{-2}\right)$ & -24 & -8 & -33 & -25 & -10 & -35 \\
LW-ToA $\left(\mathrm{Wm}^{-2}\right)$ & 1.9 & 0.3 & 3.0 & 1.9 & 0.4 & 3.0 \\
LW-sfc $\left(\mathrm{Wm}^{-2}\right)$ & 7.6 & 0.8 & 12.2 & 8.4 & 0.9 & 13.6 \\
FE-ToA $\left(\mathrm{Wm}^{-2}\right)$ & -11 & -19 & -5 & -11 & -18 & -6 \\
FE-sfc $\left(\mathrm{Wm}^{-2}\right)$ & -76 & -108 & -54 & -80 & -114 & -57 \\
AF $\left(\mathrm{Wm}^{-2}\right)$ & 20 & 4 & 30 & 21 & 5 & 32 \\
AOD & 0.52 & 0.14 & 0.78 & 0.54 & 0.17 & 0.79 \\
CB $\left(\mathrm{g} \mathrm{m}^{-2}\right)$ & 0.63 & 0.09 & 0.99 & 0.63 & 0.09 & 1.0 \\
$T\left({ }^{\circ} \mathrm{C}\right)$ & 27.34 & 20.46 & 32.00 & 27.79 & 20.87 & 32.48 \\
WS $\left(\mathrm{m} \mathrm{s}^{-1}\right)$ & 5.17 & 4.88 & 5.36 & 4.97 & 4.54 & 5.27 \\
\hline
\end{tabular}

Ground based measurements of AOD and shortwave irradiance at the Mediterranean island of Lampedusa during 2003 and 2004 were recently used by di Sarra et al. (2008) to estimate daily average values of the SW-sfc aerosol radiative forcing. They found that at the equinox the average AOD at $496 \mathrm{~nm}$ was $0.35 \pm 01$ and that the forcing was about of $-24 \mathrm{Wm}^{-2}$ for desert dust. Meloni et al. (2005) used an observation based radiative transfer model to calculate at Lampedusa daily average values of the SW aerosol forcing both at the ToA and surface during the Sahara dust outbreak on 18 May 1999. They found that the aerosol forcing was -27.6 and $-3.6 \mathrm{Wm}^{-2}$ at the surface and ToA, respectively. The measured AOD around $60^{\circ}$ solar zenith angle was 0.49 at $550 \mathrm{~nm}$. The above reported AODs and aerosol radiative forcing estimates are in satisfactory agreement with the RegCM3 estimates (Figs. 4a, 8 and 9) even if they refer to different dust outbreaks than the ones analyzed in this paper. Observation-based aerosol properties also were used by Tafuro et al. (2008) to initialize radiative transfer simulations. They also found results consistent with the ones of this paper by analyzing the Sahara dust outbreak of 18 July 2005.

The instantaneous aerosol forcing is characterized by a larger variability range over the model domain. In particular, the instantaneous (12:00 UTC) SW aerosol forcing gets values up to $75 \mathrm{Wm}^{-2}$ and $-470 \mathrm{Wm}^{-2}$, at the ToA and surface, respectively either on 17 and 24 July. Significantly larger instantaneous aerosol radiative forcing estimates have been reported by Perez et al. (2006) by analyzing a Saharan dust outbreak over the Mediterranean basin. A system based on the limited-area NCEP/Eta model as an atmospheric driver of the DREAM model was used by Perez et al. (2006) for the simulation of a major dust outbreak that occurred in the Mediterranean region on 11-13 April 2002. According to
Perez et al. (2006), instantaneous (12:00 UTC) AODs at 550 $\mathrm{nm}$ reach the value of 3.5 over the Algeria/Tunisia/Libya border on 12 April and vary within the $0.5-3$ range over Italy. In addition they show that the instantaneous (12:00 UTC) SWToA forcing is positive both over Sahara and Central Europe lands affected by dust intrusion, reaching values as high as $500 \mathrm{Wm}^{-2}$. Conversely, the instantaneous (12:00 UTC) SW forcing at the surface is negative and reaches values smaller than $-700 \mathrm{Wm}^{-2}$ both over North-West Africa and Italy. LW aerosol forcing values by Perez et al. (2006) are also significantly larger than the one of this paper. The large modelled dust load is probably responsible for the high radiative effects by dust particle reported by Perez et al. (2006).

Table 1 provides main statistics of the daily-averaged SW aerosol forcing efficiency (FE) at the ToA and surface on 17 and 24 July, respectively. The aerosol FE is the radiative forcing produced by a unit of aerosol optical depth and is mainly dependent on aerosol size and composition. The ToA-FE varies over Sahara from $-30 \mathrm{Wm}^{-2}$ up to $50 \mathrm{Wm}^{-2}$ both on 17 and 24 July. Conversely, the ToA-FE is always negative and varies from -80 to $-30 \mathrm{Wm}^{-2}$ range over the European areas affected by dust intrusion. Aerosol FE estimates are generally in line with previous reported values (e.g. Fouquart et al., 1987; Meloni et al., 2004; Helmert et al., 2007). The different contribution of dust and anthropogenic particles, which varies with the distance from the particle sources, is mainly responsible for the different variability range of FEs over Sahara and Europe, as clearly revealed by Table 1, where mean FEs over Europe and Sahara are reported. 

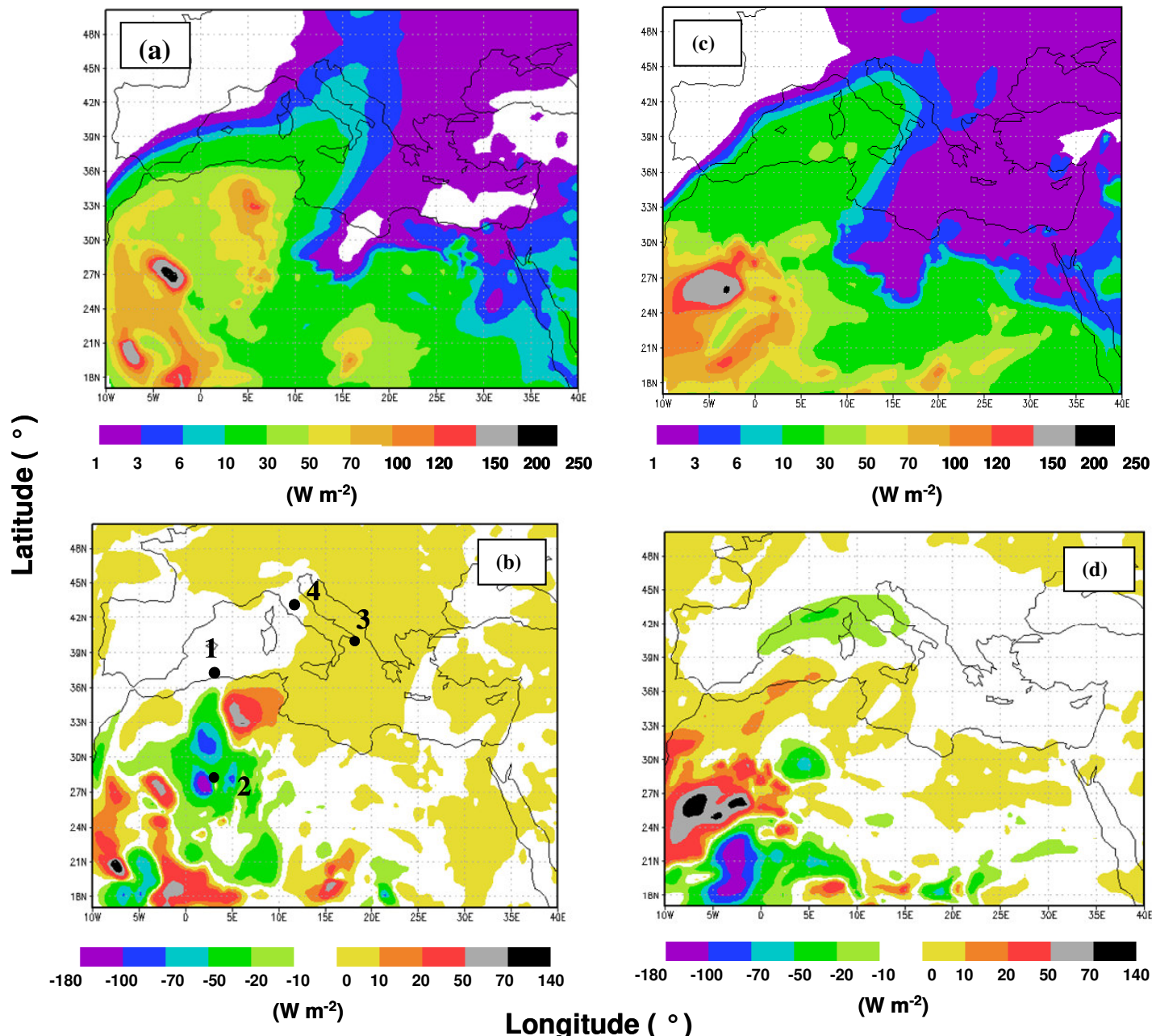

\section{Longitude $\left({ }^{\circ}\right)$}

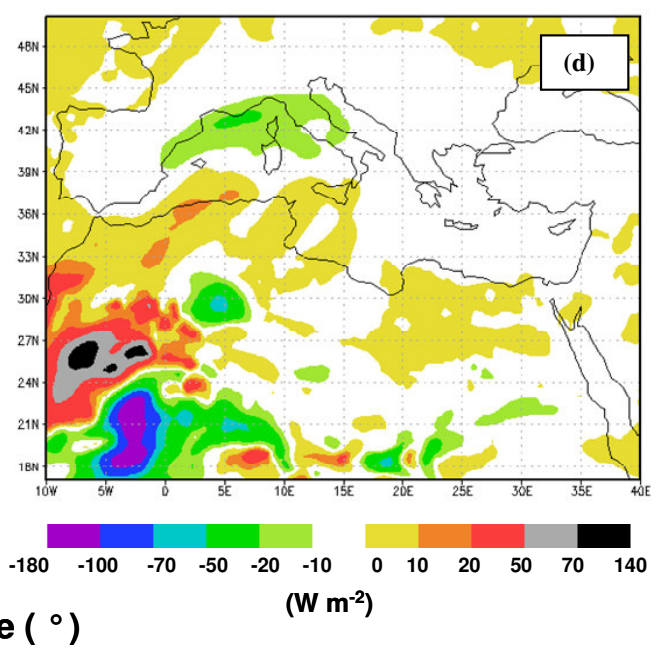

Fig. 10. REF-experiment: daily-averaged-values of the SW-atmospheric forcing (AF, $\mathrm{Wm}^{-2}$ ) for (a) 17 and (c) 24 July 2003 ; differences between REF and Exp1 SW-AF values ( $\mathrm{Wm}^{-2}$ ) for (b) 17 and (d) 24 July. Black full dots and corresponding numbers in Fig. 10b indicate the 4 sites where the simulated vertical profiles of aerosol extinction coefficient, $T$, MR and WS shown in Figs. 13 and 14 are provided.

Daily-averaged SW atmospheric forcing (AF) values are plotted in Fig. 10a and c, for 17 and 24 July, respectively. The AF, defined as the difference between ToA and surface aerosol forcing at a solar wavelength, is an indicator of aerosol effects on the atmosphere energy budget. Figure 10 shows that the SW-AF values vary up to $250 \mathrm{Wm}^{-2}$ over Africa's regions where AODs are highest (Fig. 2). Conversely, SW-AF values vary within the $3-30 \mathrm{Wm}^{-2}$ range over the European regions affected by dust intrusion (Meloni et al., 2005).

\section{Aerosol radiative feedbacks}

A simulation (Exp1) including the aerosol model without accounting for its radiative feedback was performed in order to isolate the effects of the interactive aerosol online feedback. To this end, aerosol column burden, direct radiative forcing, and meteorological parameter values in the REF- and the Exp1-simulation were analyzed and compared. Dailyaveraged aerosol column burden (CB) values $\left(\mathrm{g} \mathrm{m}^{-2}\right)$ relating to the REF simulation are shown in Fig. 11a and $b$ for 17 and 24 July, respectively. The differences between REF and Exp1 aerosol CB values are plotted in Fig. 11c and $\mathrm{d}$ for 17 and 24 July, respectively. The REF aerosol $\mathrm{CB}$ reaches values up to $18 \mathrm{~g} \mathrm{~m}^{-2}$ over the main dust sources on 17 and 24 July and takes values below $1 \mathrm{~g} \mathrm{~m}^{-2}$ over the Mediterranean Sea and Europe. This is in satisfactory agreement with the results by Helmert et al. (2007), who used a model system consisting of the chemistry-transport model MUSCAT with a dust emission scheme to simulate the Saharan dust outbreak of 13 October 2001, which affected the Central-West Mediterranean and Central Europe. 


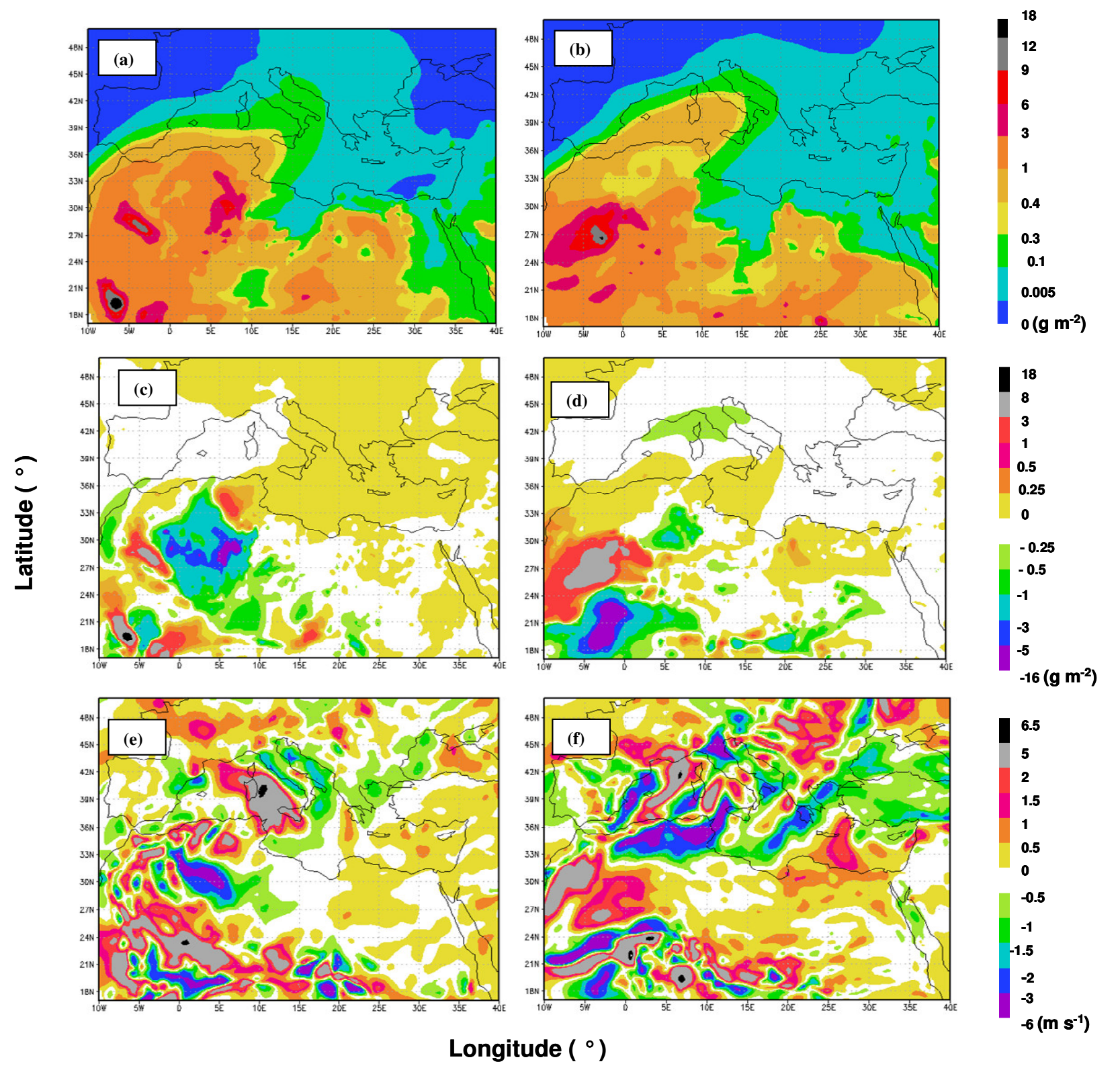

Fig. 11. REF-experiment: daily-averaged-values of the aerosol column burden $\left(\mathrm{CB}, \mathrm{g} \mathrm{m}^{-2}\right.$ ) for (a) 17 and (b) 24 July 2003 . Differences between REF and Exp1 CB values for (c) 17 and (d) 24 July. Differences between REF and Exp1 ground wind speeds (WSs) for (e) 17 and (f) 24 July.

Color-coded plots showing the daily-averaged differences between REF and Exp1 aerosol CB values (Fig. 11c and d) are very patchy: aerosol $\mathrm{CB}$ differences take positive and negative values that are comparable to the total aerosol $\mathrm{CB}$ values either over Sahara or Europe. In fact, aerosol CB differences vary over the Sahara dust sources (Fig. 1) from about $-16 \mathrm{~g} \mathrm{~m}^{-2}$ up to $18 \mathrm{~g} \mathrm{~m}^{-2}$. Conversely, CB differences vary over Europe from $-0.25 \mathrm{~g} \mathrm{~m}^{-2}$ up to $0.25 \mathrm{~g} \mathrm{~m}^{-2}$ and from $-0.50 \mathrm{~g} \mathrm{~m}^{-2}$ up to $0.25 \mathrm{~g} \mathrm{~m}^{-2}$ on 17 and $24 \mathrm{July}$, respectively. The domain-averaged aerosol CB difference is -0.1 and $-0.09 \mathrm{~g} \mathrm{~m}^{-2}$ on 17 and 24 July, respectively, de- spite the large values of local CB differences (Tables 1,2). Hence, the interactive aerosol with the RegCM3 radiation scheme decreases the daily-averaged aerosol CB over the model domain by about $14 \%$ and $12 \%$ on 17 and 24 July, respectively. Similar results have also been obtained by Heinold et al. (2007). Aerosol effects on the atmospheric dynamics and hence on dust production and advection toward Europe are responsible for the marked dependence over the whole simulation domain of aerosol $\mathrm{CB}$ values on the simulated experiment. Figure $11 \mathrm{e}$ and $\mathrm{f}$ shows the dailyaveraged differences between REF and Exp1 ground wind 


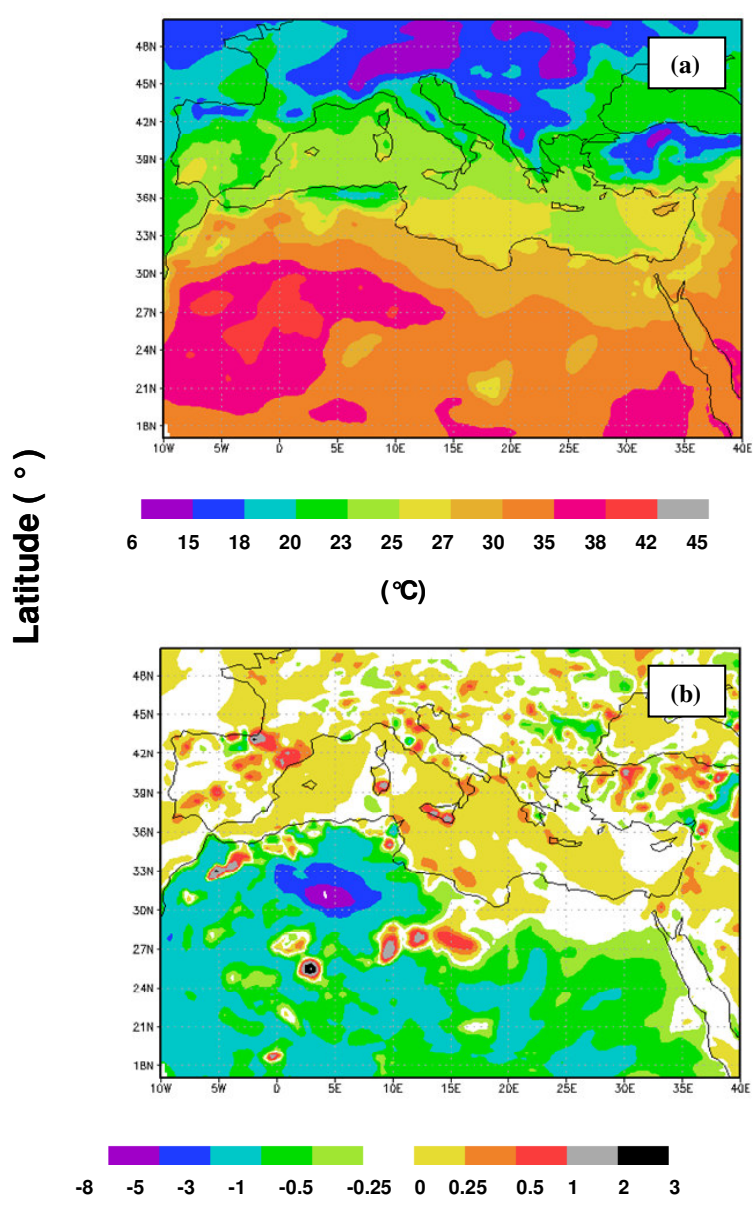

( $\left.{ }^{\circ} \mathrm{C}\right)$

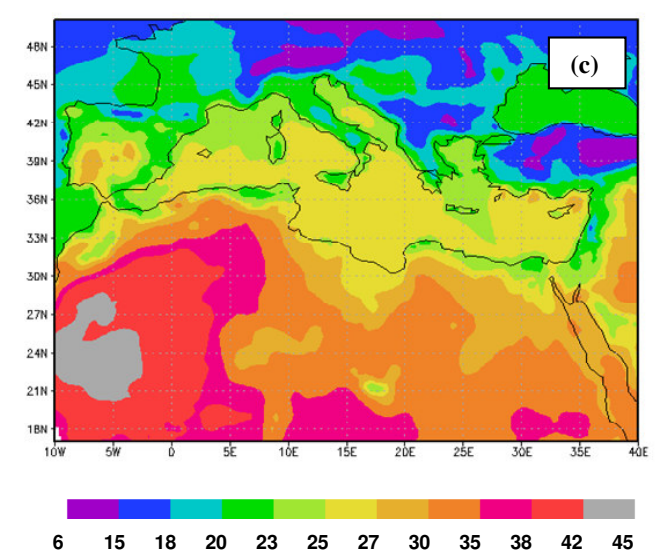

( $\left.{ }^{\circ} \mathrm{C}\right)$

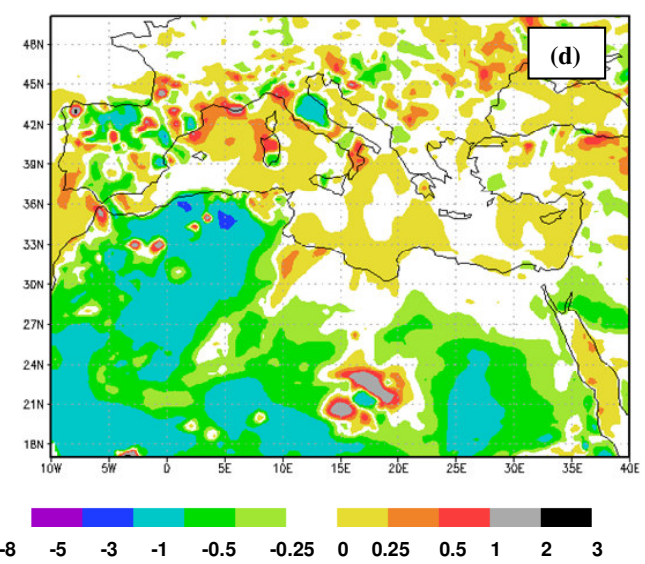

( $\left.{ }^{\circ} \mathrm{C}\right)$

\section{Longitude $\left({ }^{\circ}\right)$}

Fig. 12. REF-experiment: daily-averaged-values of the 2 m-temperature $\left({ }^{\circ} \mathrm{C}\right)$ for (a) 17 and (c) 24 July 2003 . Differences between REF and Exp1 2 m-temperature values for (b) 17 and (d) 24 July.

speeds (WS) for 17 and 24 July, respectively and it is worth noting that color-coded plots are very patchy: daily-averaged WS differences take positive and negative values that vary from $-6 \mathrm{~m} \mathrm{~s}^{-1}$ up to $6 \mathrm{~m} \mathrm{~s}^{-1}$ either over Sahara or Europe. Hence, local surface wind speeds may markedly change between the interactive- and non-interactive case. In particular, the comparison of Fig. 11a and e, and of Fig. 11b and $\mathrm{f}$, shows that WS differences are markedly large over the domain areas affected by dust transport. Daily values of ground WSs averaged both over the whole simulation domain and for the regions below and above $35^{\circ} \mathrm{N}$ are given in Table 1 and 2 for the REF-and the Exp1-simulation, respectively. The domain-averaged WS difference is 0.015 and $-0.014 \mathrm{~m} \mathrm{~s}^{-1}$ on 17 and 24 July, respectively, despite the large values of local WS differences. In addition, the mean WS difference is -0.002 and $-0.052 \mathrm{~m} \mathrm{~s}^{-1}$ on 17 and 24 July over the Western Africa domain located from $10^{\circ} \mathrm{W}$ to $15^{\circ} \mathrm{E}$, where main dust sources are located. Therefore, the decreased $\mathrm{CB}$ of the REF simulation is probably asso- ciated with less efficient dust production induced either by the lower ground wind speeds and by the increased stability due to dust-forced surface cooling (Zhang et al., 2009), as outlined below.

Daily-averaged $2 \mathrm{~m}$-temperatures for the REF simulation are plotted in Figs 12a and c for 17 and 24 July, respectively. The $2 \mathrm{~m}$-temperature averaged over the whole simulation domain is 27.34 and $27.79^{\circ} \mathrm{C}$ on 17 and 24 July, respectively (Table 1). Figures $12 \mathrm{~b}$ and d show the $2 \mathrm{~m}$-temperature differences $\left({ }^{\circ} \mathrm{C}\right)$ between REF- and Exp1-simulation for 17 and 24 July, respectively. Temperature differences $(\Delta T)$ are quite dependent on location, generally following the CB differences. $\Delta T$ takes positive and negative values and varies from about $-8^{\circ} \mathrm{C}$ up to $\sim 3{ }^{\circ} \mathrm{C}$ on 17 and 24 July, respectively. The $2 \mathrm{~m}$-temperature differences averaged over the simulation domain are $\Delta T=-0.52^{\circ} \mathrm{C}$ and $\Delta T=-0.39^{\circ} \mathrm{C}$ on 17 and 24 July, respectively. Hence, the interactive aerosol decreases the domain-average daily-mean value of the $2 \mathrm{~m}$ temperature. 

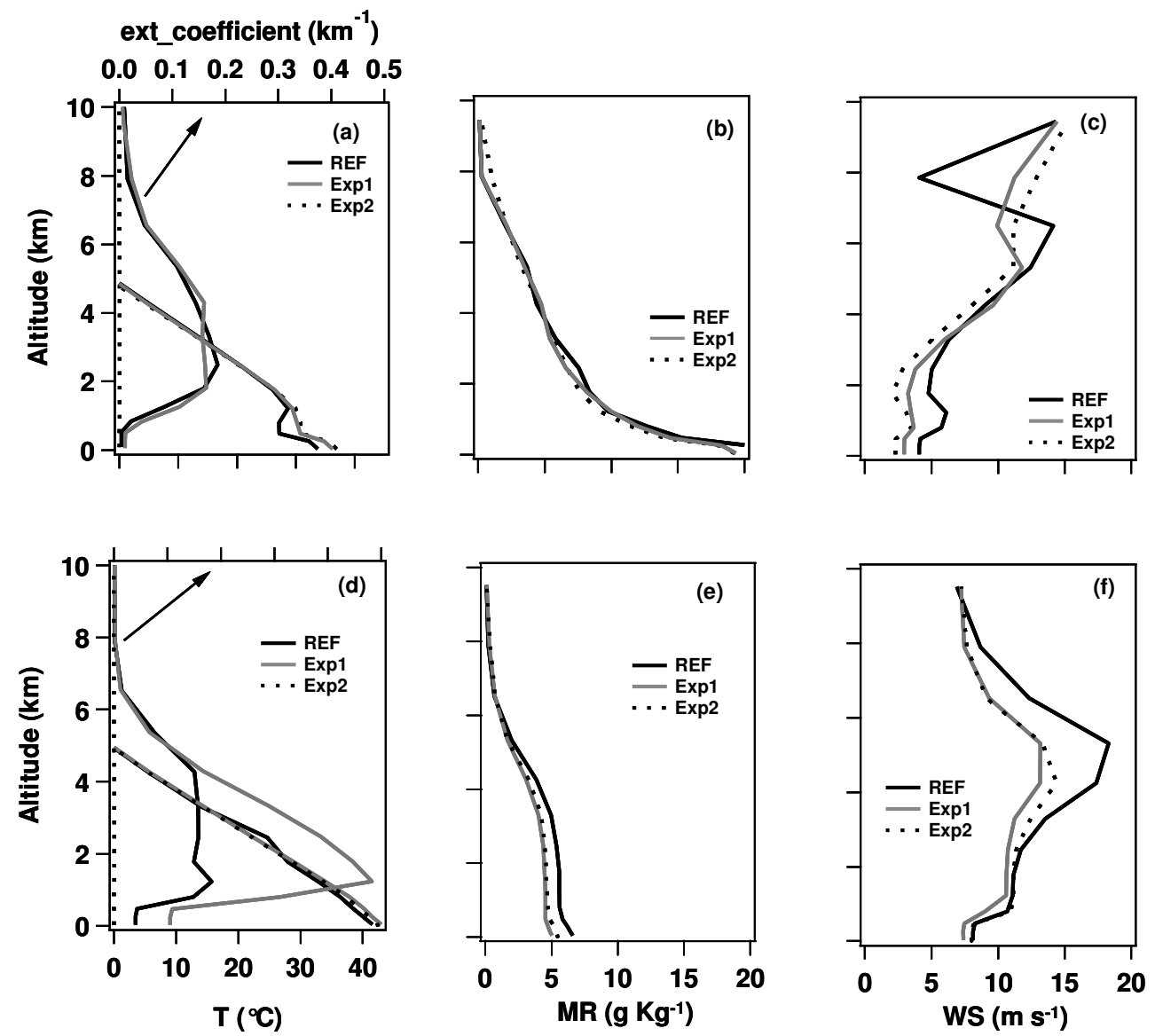

Fig. 13. Daily-averaged vertical profiles of the aerosol extinction coefficient, temperature, water vapor mixing ratio, and wind speed for 17 July 2003 at two selected North-West Africa sites: (a-c) site $1\left(36.10^{\circ} \mathrm{N}, 2.07^{\circ} \mathrm{E}\right)$ and (d-f) site $2\left(27.76^{\circ} \mathrm{N}, 2.75^{\circ} \mathrm{E}\right)$. Black-solid-line, grey-solid-line, and dotted-line relate to REF-, Exp1-, and Exp2-simulation, respectively.

Table 2. Exp1-simulation: daily-mean values of the short-wave (SW) and long-wave (LW) aerosol forcing at the top of the atmosphere (ToA) and surface (sfc), of the SW atmospheric forcing (AF), the aerosol optical depth (AOD), the aerosol column burden (CB), the 2-m temperature $(T)$, and the ground wind speed (WS) averaged over the whole simulation domain (Wh-domain) and over the simulation domain located above $35^{\circ} \mathrm{N}\left(\mathrm{a}-35^{\circ} \mathrm{N}\right)$ and below $35^{\circ} \mathrm{N}\left(\mathrm{b}-35^{\circ} \mathrm{N}\right)$ by the REF-simulation and for 17 and $24 \mathrm{July}$.

\begin{tabular}{lrrrrrr}
\hline Parameters & Wh-domain & $\begin{array}{r}\text { 17-July } \\
\mathrm{a}-35^{\circ} \mathrm{N}\end{array}$ & $\mathrm{b}-35^{\circ} \mathrm{N}$ & Wh-domain & $\begin{array}{r}\text { 24-July } \\
\mathrm{a}-35^{\circ} \mathrm{N}\end{array}$ & $\mathrm{b}-35^{\circ} \mathrm{N}$ \\
\hline SW-ToA $\left(\mathrm{Wm}^{-2}\right)$ & -3.2 & -3.8 & -2.7 & -3.5 & -4.9 & -2.6 \\
SW-sfc $\left(\mathrm{Wm}^{-2}\right)$ & -25 & -8 & -37 & -25 & -8 & -37 \\
LW-ToA $\left(\mathrm{Wm}^{-2}\right)$ & 2.5 & 0.3 & 4.0 & 2.6 & 0.5 & 3.9 \\
LW-sfc $\left(\mathrm{Wm}^{-2}\right)$ & 9.1 & 0.8 & 14.7 & 8.6 & 1.2 & 13.6 \\
AF $\left(\mathrm{Wm}^{-2}\right)$ & 22 & 4 & 34 & 24 & 7 & 36 \\
AOD & 0.57 & 0.14 & 0.85 & 0.65 & 0.23 & 0.94 \\
CB $\left(\mathrm{g} \mathrm{m}^{-2}\right)$ & 0.73 & 0.09 & 1.17 & 0.72 & 0.13 & 1.1 \\
$T\left({ }^{\circ} \mathrm{C}\right)$ & 27.86 & 20.49 & 32.8 & 28.18 & 20.96 & 33.07 \\
WS $\left(\mathrm{m} \mathrm{s}^{-1}\right)$ & 5.15 & 4.86 & 5.35 & 5.09 & 4.86 & 5.24 \\
\hline
\end{tabular}



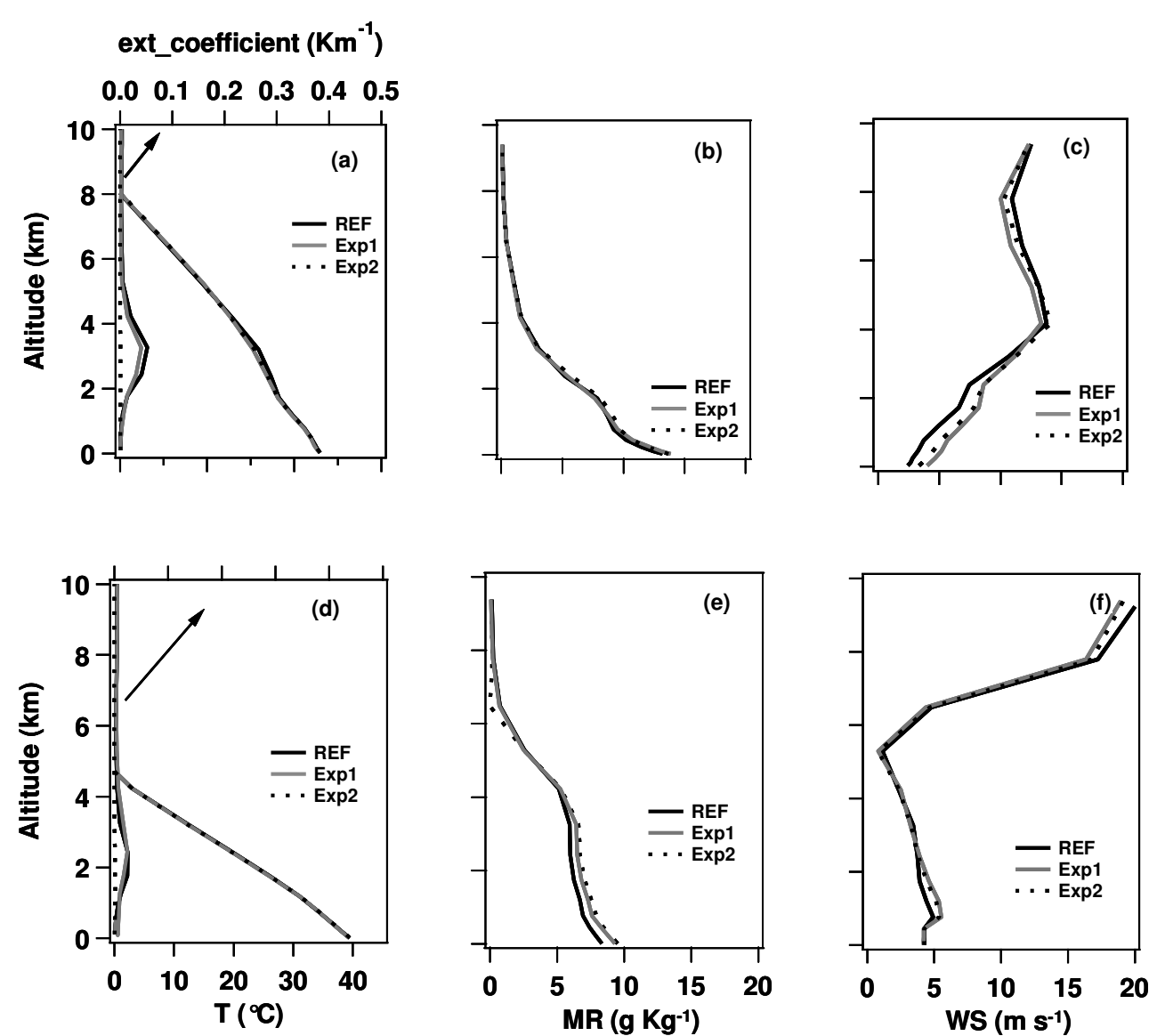

Fig. 14. Daily-averaged vertical profiles of the aerosol extinction coefficient, temperature, water vapor mixing ratio, and wind speed for 17 July 2003, at two selected Italian sites: (a-c) site $3\left(40.38^{\circ} \mathrm{N}, 18.06^{\circ} \mathrm{E}\right)$ and (d-f) site $4\left(42.40^{\circ} \mathrm{N}, 12.43^{\circ} \mathrm{E}\right)$. Black-solid-line, dottedline, grey-solid-line, and dotted-line relate to REF-, Exp1-, and Exp2-simulation, respectively.

Daily-averaged vertical profiles of the aerosol extinction coefficient at $550 \mathrm{~nm}$, temperature $(T)$, water vapor mixing ratio (MR), and wind speed (WS) at randomly selected sites are plotted in Figs. 13 and 14 to better highlight aerosol online feedback effects on the vertical profiles of atmospheric parameters and of the aerosol extinction coefficient. Figure 13a-c shows extinction coefficient, $T$, MR, and WS vertical profiles of 17 July for the REF-case (black line) and the Exp1 simulation (grey line) at a selected North-West Sahara site: site $1\left(36.10^{\circ}\right.$ N, $2.07^{\circ}$ E, Fig. 10b). It is worth noting that $T$, MR, and WS vertical profiles depends on simulated experiment. In particular, Fig. 13a shows that Exp1-temperatures (grey profile) are larger than REFtemperatures up to about $1.1 \mathrm{~km}$ then the differences between the two profiles reduce with altitude. This result shows that the aerosol online feedback increases the aerosol cooling effect in the lower troposphere, in accordance with Fig. 12b. REF-simulation MR values are slightly larger than corresponding Exp1-MRs up to about $3 \mathrm{~km}$. Then, the differences between the two profiles reduce with altitude. WS vertical profiles are also quite dependent on simulation assump- tions. Figure 13c shows that Exp1-WSs (grey profile) are significantly lower than corresponding REF-scenario-WSs at least up to about $7 \mathrm{~km}$. Figure $13 \mathrm{~d}-\mathrm{f}$ shows aerosol extinction coefficient, $T$, MR, and WS vertical profiles provided by the model on 17 July at a different North-West Sahara location: site $2\left(27.76^{\circ} \mathrm{N} ; 2.75^{\circ} \mathrm{E}\right.$, Fig. $\left.10 \mathrm{~b}\right)$ that is rather close to a main dust source. We observe that the interactive aerosol simulation (REF) produces in the lower troposphere lower temperatures and larger MR and WS values than the Exp1-simulation, in accordance with Fig. 13a-c. It is also worth noting at site 2 , that the interactive aerosol significantly lowers the aerosol load located from about 0.5 to $4 \mathrm{~km}$ even if it is responsible for larger wind speeds. In fact, the REF-extinction coefficient takes values $\cong 0.3 \mathrm{~km}^{-1}$ from 0.5 to $4 \mathrm{~km}$ while, the Exp1-extinction coefficient varies $\mathrm{up} \cong 0.5 \mathrm{~km}^{-1}$ from 0.5 to $4 \mathrm{~km}$. On the contrary, Fig. 13a referring to a site that is far away from dust sources (Fig. 10b) shows that the aerosol vertical distribution is poorly affected by the interactive aerosol online feedback. 

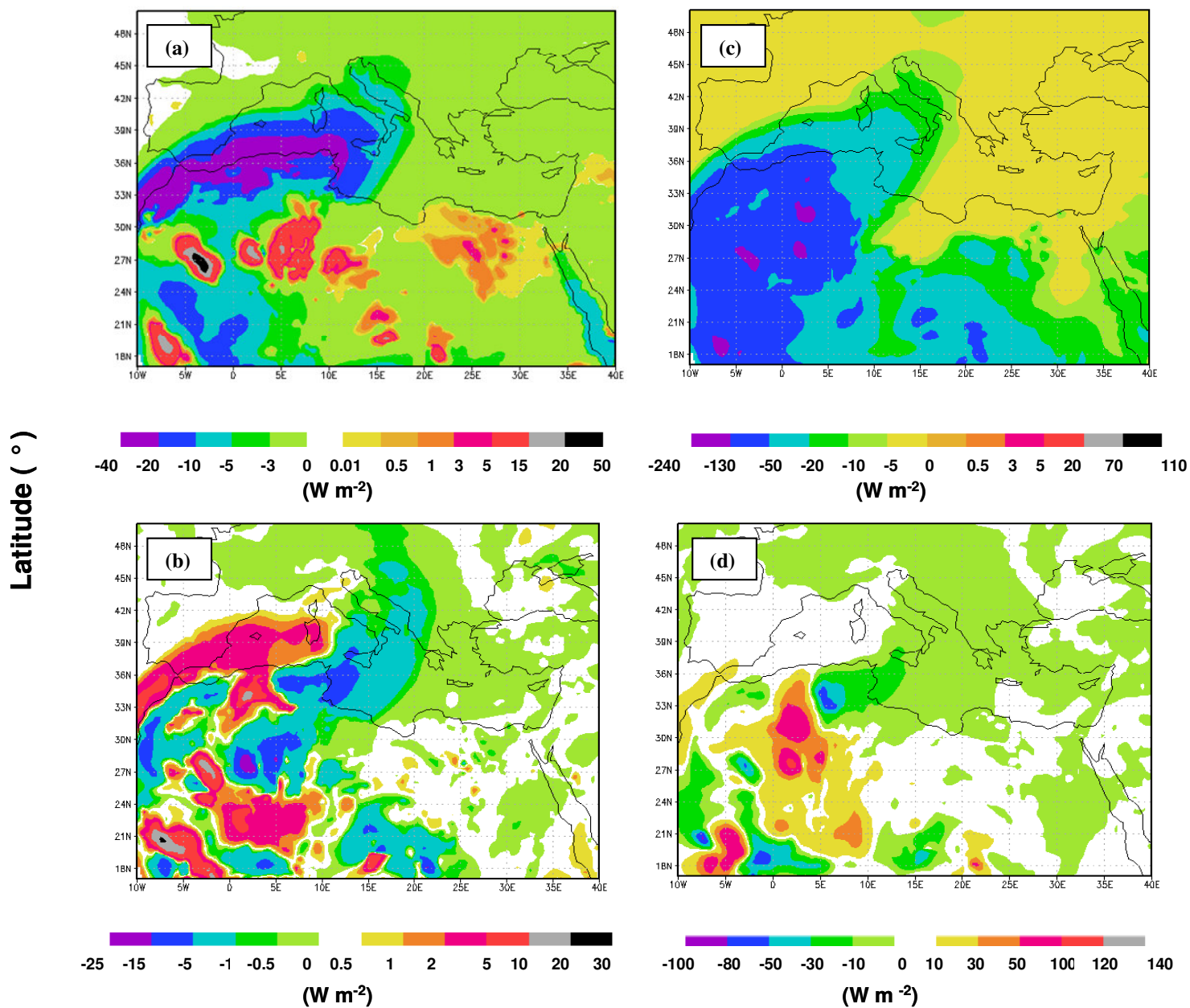

\section{Longitude $\left({ }^{\circ}\right)$}

Fig. 15. Exp1-simulation: daily averaged values of the SW aerosol forcing ( $\mathrm{Wm}^{-2}$ ) at the (a) ToA and (b) surface for $17 \mathrm{July} 2003$. Differences between REF and Exp1 SW aerosol forcing values at the (c) ToA and (d) surface.

Figure 14a-f show the aerosol extinction coefficient, $T$, MR, and WS vertical profiles provided by the REF- (black line) and Exp1-simulation (grey line) on 17 July at two randomly selected Italian sites located at $40.38^{\circ} \mathrm{N}-18.06^{\circ} \mathrm{E}$ (site 3) and at $42.40^{\circ} \mathrm{N}-12.43^{\circ} \mathrm{E}$ (site 4), respectively (Fig. 10b). The differences between REF and Exp1 profiles are on average smaller than the ones in Fig. 13. This is due to the fact that the radiative aerosol effects depend on the aerosol column burden, which over Italy is significantly smaller than that over the Sahara.

The differences between daily-averaged SW-AF values by the REF- and the Exp1-simulation for 17 and 24 July are shown in Fig. 10b, d, respectively. SW-AF differences significantly vary from site to site especially over the Sahara. As a consequence, aerosol effects on atmospheric dynamics may significantly change with location over the Sahara. Negative values of the SW-AF differences (Fig. 10b-d) indicate that the Exp1-simulation is responsible for an increase of the energy stored within the atmosphere and it is worth mentioning that larger atmospheric forcing values lead to a stabilizing effect of the atmospheric stratification. Figure $10 \mathrm{~b}$ and $\mathrm{d}$ show that daily-averaged SW-AF differences vary over the Sahara from -180 up to $140 \mathrm{Wm}^{-2}$ on 17 and 24 July, respectively. However, SW-AF differences averaged over Sahara lead to a mean difference of $-4 \mathrm{Wm}^{-2}$ on 17 and 24 July, respectively. Hence, the aerosol SW-AF mainly decreases over Africa if the aerosol online feedback on the radiation budget is accounted for, in accordance with the results on the CB differences. In fact, the comparison of Figs. $10 \mathrm{~b}$ and $11 \mathrm{~b}$ and of Fig. 10d and 11d clearly reveals the strong relationship between SW-AF differences and aerosol CB differences. Daily-averaged SW-AF differences are significantly smaller over Europe.

Figure $15 \mathrm{a}$ and $\mathrm{c}$ show the 17-July-daily-averaged SW radiative forcing at the ToA and surface, respectively for the Exp1-simulation. The differences between REF and Exp1 radiative forcing values are plotted in Fig. 15b and $\mathrm{d}$ for the ToA and surface, respectively. On average the 

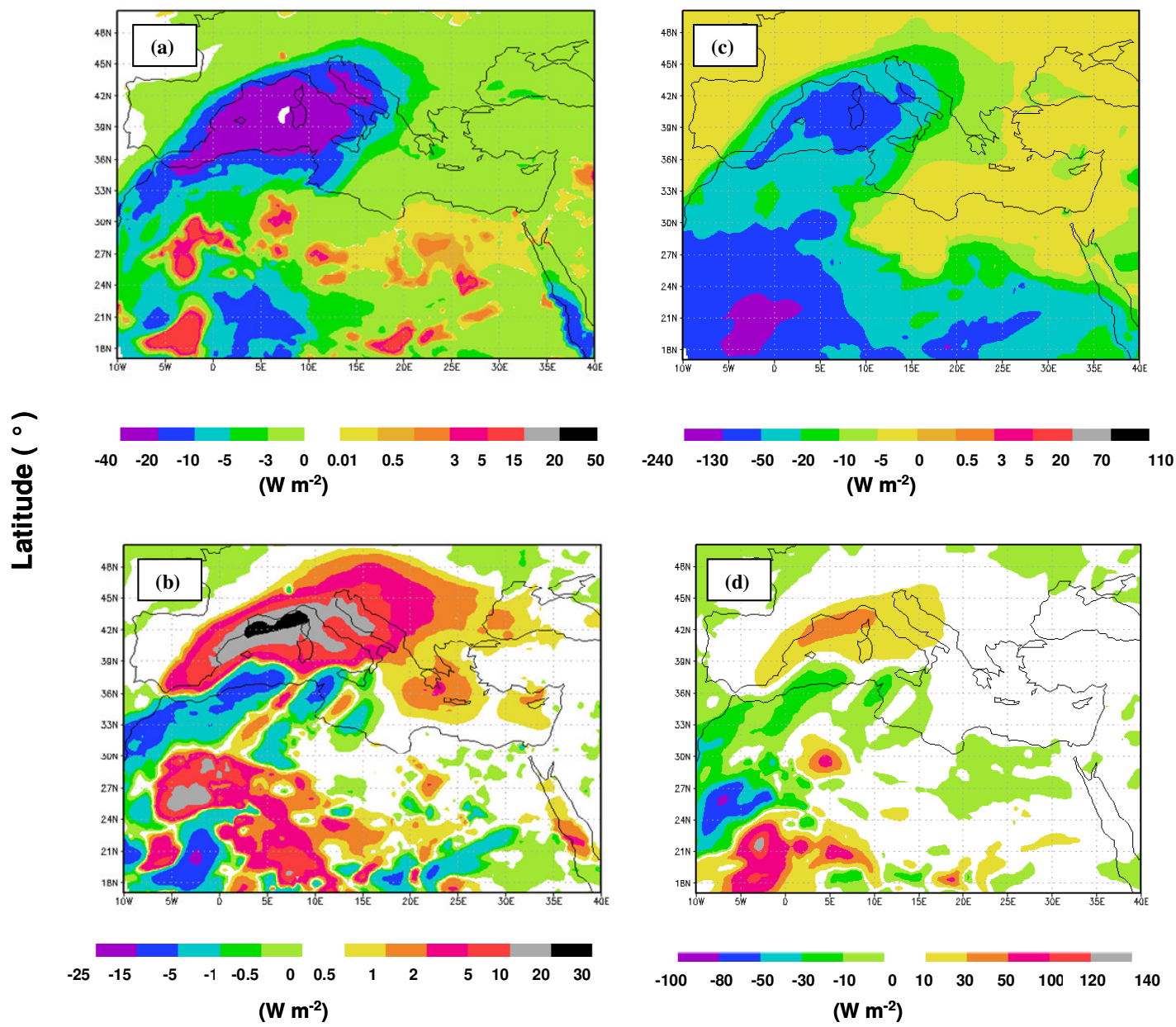

\section{Longitude $\left({ }^{\circ}\right)$}

Fig. 16. Exp1-simulation: daily averaged values of the SW aerosol forcing $\left(\mathrm{Wm}^{-2}\right)$ at the (a) ToA and (c) surface for 24 July 2003. Differences between REF and Exp1 SW aerosol forcing values at the (b) ToA and (d) surface.

Exp1-simulation strengthens the aerosol radiative forcing at the surface. In fact, the REF and Exp1 SW radiative forcing at the surface, averaged over the whole simulation domain, is -24 and $-25 \mathrm{Wm}^{-2}$, respectively on 17 July. Conversely, at the ToA, the REF and Exp1 SW radiative forcing averaged over the whole domain is -3.4 and $-3.2 \mathrm{Wm}^{-2}$, respectively on 17 July. However, the patchy pattern of Fig. 15b and d shows that the differences between REF and Exp1 values are locally significantly larger both at the ToA and surface.

Figure 16a and c show the daily-averaged SW radiative forcing at the ToA and surface, respectively for 24 July and for the Exp1-simulation. The differences between REF and Exp1 values are plotted in Fig. 16b and d for the ToA and surface, respectively. The strengthening of the surface SW radiative forcing if the aerosol online feedback on the radiation budget is not accounted for is also revealed by Fig. 16d. The REF and Exp1 SW radiative forcing averaged over the whole domain is -24 and $-25 \mathrm{Wm}^{-2}$, respectively at the surface.

\section{Interactive mineral dust radiative effects}

A simulation without any desert aerosol affecting the radiation (Exp2) was performed to isolate the radiative forcing by mineral dust. Figure $17 \mathrm{a}$ and $\mathrm{b}$ show the Exp2daily-averaged SW aerosol forcing at the ToA and surface, respectively for 17 July. The SW aerosol forcing by the $\mathrm{SO}_{2} / \mathrm{SO}_{4}^{2-}$ system, hydrophobic and hydrophilic black carbon and organic carbon varies from -1.6 to $0.5 \mathrm{Wm}^{-2}$ and from $-4.5 \mathrm{Wm}^{-2}$ to negligible values at the ToA (Fig. 17a) and surface (Fig. 17b), respectively. The daily averaged LW aerosol forcing is close to negligible both at the ToA and surface. The comparison of Fig. 8a and b to Fig. 17a and $b$ clearly shows the significant role of mineral dust on ToA and surface aerosol forcing. Exp2-SW aerosol forcing values averaged over the whole simulation domain and over the simulation domain above and below $35^{\circ} \mathrm{N}$ are given in Table 3, in addition to daily-averaged values of the AOD, aerosol $\mathrm{CB}$, and $2 \mathrm{~m}$-temperature. Table 3 shows that the 

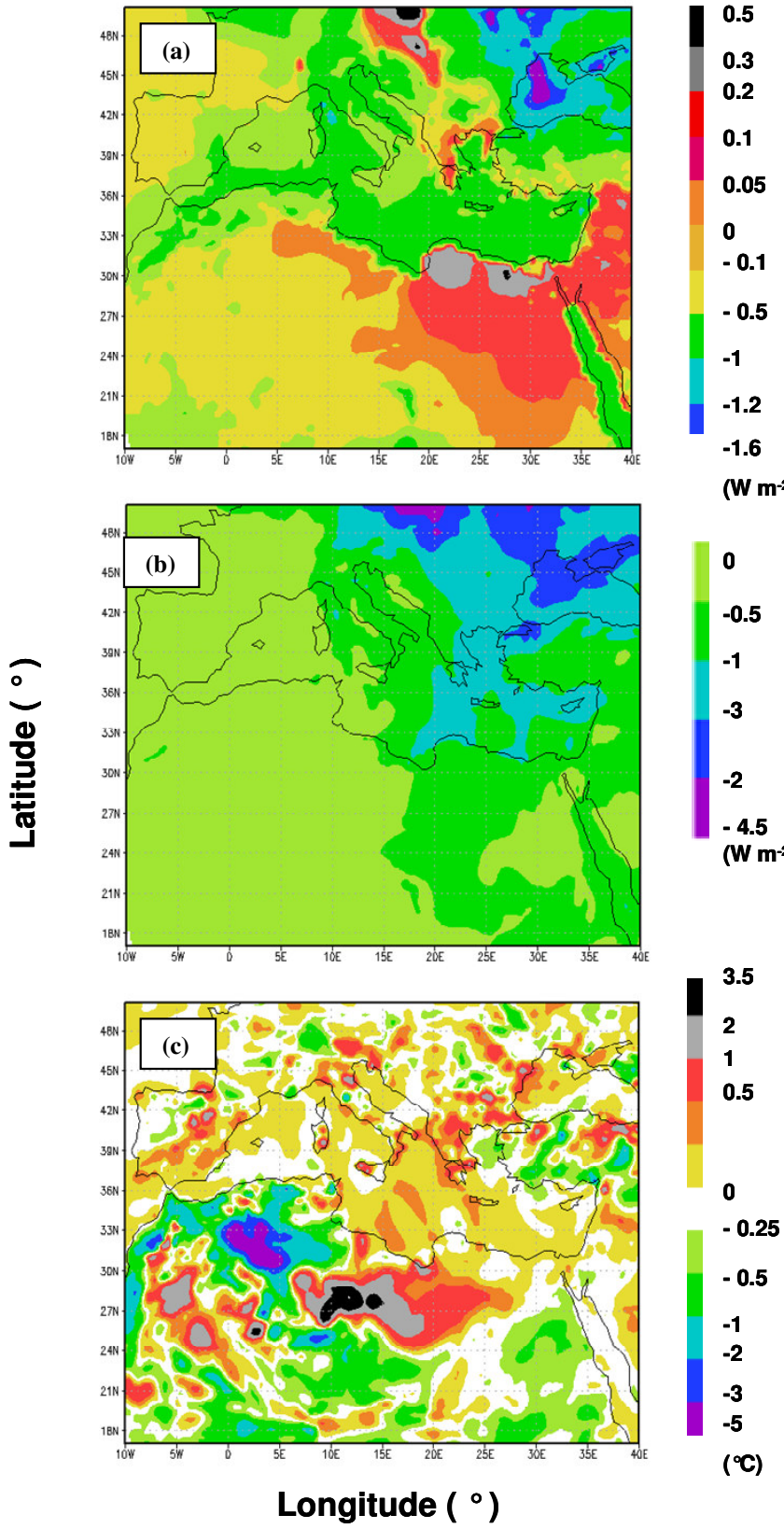

$\left({ }^{\circ} \mathrm{C}\right)$

Fig. 17. Exp2-simulation: daily averaged values of the SW-forcing $\left(\mathrm{Wm}^{-2}\right)$ at the (a) ToA and (b) surface on 17 July 2003. (c) Differences between REF and Exp2 2 m-temperature values $\left({ }^{\circ} \mathrm{C}\right)$.

AOD averaged over the whole simulation domain is equal to 0.006 and that the aerosol forcing averaged over the whole simulation domain is -0.06 and $-0.6 \mathrm{Wm}^{-2}$ at the ToA and surface, respectively. We believe that the underestimation of contribution by the $\mathrm{SO}_{2} / \mathrm{SO}_{4}^{2-}$ system, hydrophobic and hydrophilic black carbon and organic carbon (anthropogenic aerosol component) is probably responsible for the rather low aerosol radiative forcing and AOD values provided by Exp2 simulation. Several experimental-based studies have shown
Table 3. Exp2-simulation: 17 July-daily averaged values of the short-wave (SW) aerosol forcing at the top of the atmosphere (ToA) and surface (sfc), the SW atmospheric forcing (AF), the aerosol optical depth (AOD), the aerosol column burden (CB), and of the temperature $(T)$ averaged over the whole simulation domain (Wh-domain) and over the simulation domain located above $35^{\circ} \mathrm{N}$ $\left(\mathrm{a}-35^{\circ} \mathrm{N}\right)$ and below $35^{\circ} \mathrm{N}\left(\mathrm{b}-35^{\circ} \mathrm{N}\right)$.

\begin{tabular}{|c|c|c|c|}
\hline Parameters & Wh-domain & $\begin{array}{r}17-J u l y \\
\mathrm{a}-35^{\circ} \mathrm{N}\end{array}$ & $\mathrm{b}-35^{\circ} \mathrm{N}$ \\
\hline SW -ToA $\left(\mathrm{Wm}^{-2}\right)$ & -0.06 & -0.17 & 0.02 \\
\hline $\mathrm{SW}-\mathrm{sfc}\left(\mathrm{Wm}^{-2}\right)$ & -0.6 & -0.8 & -0.4 \\
\hline $\mathrm{AF}\left(\mathrm{Wm}^{-2}\right)$ & 0.5 & 0.6 & 0.4 \\
\hline AOD & 0.006 & 0.007 & 0.006 \\
\hline $\mathrm{CB}\left(\mathrm{g} \mathrm{m}^{-2}\right)$ & 0.0012 & 0.0010 & 0.0014 \\
\hline$T\left({ }^{\circ} \mathrm{C}\right)$ & 27.46 & 20.48 & 32.16 \\
\hline
\end{tabular}

that the anthropogenic aerosol is responsible for larger AODs and hence for lager aerosol direct radiative effects over the Mediterranean basin (e.g. Bergamo et al., 2008).

Figure $17 \mathrm{c}$ shows the $2 \mathrm{~m}$-temperature differences between REF- and Exp2-simulation for 17 July. Temperature differences vary from $-5^{\circ} \mathrm{C}$ to $3.5^{\circ} \mathrm{C}$. However, the mean temperature difference over the whole simulation domain and above and below $35^{\circ} \mathrm{N}$ is $-0.10,-0.01$, and $-0.16^{\circ} \mathrm{C}$, respectively.

Interactive anthropogenic aerosol effects on meteorological parameter vertical profiles can be inferred from Figs. 13 and 14 where $T$, MR, and WS vertical profiles for 17 July by the Exp2-simulation are plotted (dotted line). The $T$, MR, and WS vertical profiles in Exp2 are generally close to the corresponding ones in Exp1. It is also worth noting that extinction coefficients due to the $\mathrm{SO}_{2} / \mathrm{SO}_{4}^{2-}$ system, hydrophobic and hydrophilic black carbon and organic carbon, take values over Africa and the Central Mediterranean that are on average 500 and 100 times smaller than the corresponding ones due to desert dust.

\section{Conclusions}

The regional climate model RegCM3 coupled with a radiatively active aerosol model with online feedback on the radiation budget has been used to evaluate the aerosol radiative forcing of dust intrusion events over the Mediterranean basin. In particular, two major dust outbreaks with origin in North-West Sahara were analyzed, which occurred on 17 and 24 July, 2003. Both dust outbreaks carried significant amounts of mineral dust over the Central Mediterranean Sea and continental Europe. Even if several papers have been published on this subject, dust particles radiative effects are still not well parameterized in numerical models, as revealed by the differences between results from different models and between numerical and experimental data. 
The RegCM3 simulation was first validated at selected Central Mediterranean sites against a range of observations: AOD by satellite (MODIS) and AERONET sun/sky radiometer measurements, extinction coefficient vertical profiles by lidar measurements, temperature vertical profiles by radio sounding measurements. We find that RegCM3 is able to capture the dust outbreaks during July 2003, with a generally satisfactory agreement with observations. The main deficiency of the simulations is an underestimate of aerosol amounts at locations far from the dust source, particularly in the lower troposphere. This is probably an indication of weak long range transport, although a contribution to it is also given by an underestimate of background anthropogenic aerosols (probably related to the limited number of aerosol types in the model). Another factor affecting this result is likely due to an incorrect choice of dust optical and microphysical properties. Work is on progress to investigate how uncertainties on aerosol size distributions and refractive indices affect model results.

The simulation of SW and LW direct radiative forcing shows a prevalence of negative values (cooling) at the surface both over the Sahara and Europe. Conversely, the daily net ToA forcing averaged over the Sahara is positive $\left(0.4 \mathrm{Wm}^{-2}\right)$ or nearly close to zero for the two outbreaks of 17 and 24 July. This is a consequence of the offsetting effect of the LW-ToA direct aerosol forcing. We also found that the daily SW-ToA forcing is on average positive (up to $50 \mathrm{Wm}^{-2}$ ) close to the source regions where the dust amounts are large. Over Europe, a negative net ToA-radiative effect is found.

The comparison of REF- and Exp1-simulation results illustrates the significant role of the aerosol online feedback on atmospheric dynamics and hence on dust production and advection toward Europe: local changes were significantly larger than domain-averaged changes. The daily-averaged aerosol CB decreases by $14 \%$ and $12 \%$ over the simulation domain on 17 and 24 July, if the aerosol online feedback on the radiation budget is accounted for, while, the daily-mean 2 m-temperature decreases by 0.53 and $0.39^{\circ} \mathrm{C}$ on 17 July and 24 July, respectively. The analysis of daily-averaged vertical profiles of temperature, water vapor mixing ratio (MR), and wind speed (WS) at two randomly selected sites close to the dust sources shows that temperature decreases at least up to $1 \mathrm{~km}$, while MR and WS increase at least up to $4 \mathrm{~km}$ if the aerosol online feedback is accounted for. In fact, the daily-averaged SW radiative forcing at the surface increases by about $7 \%$ and $2 \%$ over the whole simulation domain on 17 and 24 July, respectively, whereas the daily-averaged SW-AF decreases by $9 \%$ and $12 \%$ when including the aerosol online feedback. Finally, a sensitivity experiment without the inclusion of dust shows that Saharan dust is by far the greatest contributor to the total aerosol radiative forcing during dust outbreaks. However, this result is also probably due to the underestimation over the model domain of the contribution by the $\mathrm{SO}_{2} / \mathrm{SO}_{4}^{2-}$ system, hydrophobic and hydrophilic black carbon and organic carbon.
Our results show the importance of considering aerosol particles and corresponding radiative effects over the Mediterranean region. The aerosol effects on the atmosphere radiative budget may significantly change within few tens of kilometers following variations in the aerosol $\mathrm{CB}$. Hence, the importance of using high resolution regional climate models to properly account for aerosol effects on climate is highlighted. Work is on progress to improve parameterization of aerosol optical and microphysical properties in RegCM3 by also including sea-salt particles and a full treatment of organic aerosols.

Acknowledgements. M. Santese has carried out this work with the support of a post-doc fellowship by Centro euroMediterraneo per i Cambiamenti Climatici (CMCC). This work also has been supported by Ministero dell' Istruzione dell'Università e della Ricerca of Italy, (Programma di Ricerca di Interesse Nazionale 2006. Prot. 2006027825), by the European Project EARLINET-ASOS (20062011, contract n. 025991), by Progetto FISR AEROCLOUDS. The authors kindly acknowledge Principal Investigators of the AERONET stations of Rome, Oristano, Etna, and Lampedusa. G. Gobbi is kindly acknowledged for providing lidar profiles at Etna's site.

Edited by: A. Pszenny

\section{References}

Alfaro, S. C. and Gomes, L.: Modelling mineral aerosol production by wind erosion: Emission intensities and aerosol size distributions in source areas, J. Geophys. Res., 106, 18075-18084, 2001.

Andreae, T. W., Andreae, M. O., and Ichoku, C.: Light scattering by dust and anthropogenic aerosol at a remote site in the Negev desert, Israel, J. Geoph. Res., 107(D2), 3-1, doi:10.1029/2001JD900252, 2002.

Balkanski, Y., Schulz, M., Claquin, T., and Guibert, S.: Reevaluation of Mineral aerosol radiative forcings suggests a better agreement with satellite and AERONET data, Atmos. Chem. Phys., 7, 81-95, 2007,

http://www.atmos-chem-phys.net/7/81/2007/.

Bellantone V., Carofalo, I., De Tomasi, F., Perrone, M. R., Santese, M., Tafuro, A. M., and Turnone, A.: In situ samplings and remote sensing measurements to characterize aerosol properties over South-East Italy, J. Atmos. Oceanic Technol, 25, 13411356, 2008.

Bergamo, A., Tafuro, A. M., Kinne, S., De Tomasi, F., and Perrone, M. R.: Monthly-averaged anthropogenic aerosol direct radiative forcing over the Mediterranean based on AERONET aerosol properties, Atmos. Chem. Phys., 8, 6995-7014, 2008, http://www.atmos-chem-phys.net/8/6995/2008/.

Bergamo A., De Tomasi, F., and Perrone, M.R.: Direct radiative effects by anthropogenic particles at a polluted site: Rome (Italy), Il Nuovo Cimento, 31, 4, doi:10.1393/ncc/i2009-10320-1, 2009.

Chin, M., Kahn, R. A., Swartz, S. E.: Atmospheric Aerosol Properties and Climate Impacts, U.S. Climate Change Science Program (CCSP), Synthesis and Assessment Product 2.3, NASA Goddard Space Flight Center, 2009. 
De Tomasi, F. and Perrone, M. R.: Lidar measurements of tropospheric water vapor and aerosol profiles over southeastern Italy, J. Geophys. Res., 108, 4286-4297, 2003.

De Tomasi, F., Tafuro, A. M., and Perrone, M. R.: Height and seasonal dependence of aerosol optical properties over south-east Italy, J. Geophys. Res., 111, D10203, doi:10.1029/2005JD006779, 2006.

Dickinson, R. E., Henderson-Sellers, A. and Kennedy P. J.: Biosphere-Atmosphere Transfer Scheme (BATS) Version 1E as coupled to the NCAR Community Climate Model, NCAR Tech. rep. TN-387+STR, 72 pp., 1993.

Di Sarra, A., Pace, G., Meloni, D., De Silvestri, L., Piacentino, S., and Monteleone, F.: Surface shortwave radiative forcing of different aerosol types in the central Mediterranean, Geophys. Res. Lett., 35, L02714, doi:10.1029/2007GL032395, 2008.

Dubovik, O., King, M. D.: A flexible inversion algorithm for retrieval of aerosol optical properties from Sun and sky radiance measurements. J. Geophys. Res., 105, 20673-20696, 2000.

Fouquart, Y., Bonnel, B., Broigniez, G., Buriez, J. C., Smith, L., Morerette, J. J., and Cerf, A.: Observations of Saharan aerosols: Results of ECLATS field experiment, Part II: broandband radiative characteristics of the aerosols and vertical radiative flux divergence, J. Clim. Appl. Meteorol., 26, 38-52, 1987.

Giorgi, F. and Bi, X. Q.: A study of internal variability of a regional climate model, J. Geophys. Res., 105(D24), 29503-29521, 2000.

Giorgi F.: Climate change hot-spots, Geophys. Res. Letts., 33(8), L08707, doi:10.1029/2006GL025734, 2006.

Gobbi, G. P., Barnaba, F., Giorgi, R., Santacasa, A.: Altituderesolved properties of a Saharan-Dust event over the Mediterranean, Atmos. Environ. 34, 5119-5127, 2000.

Grell, G. A.: Prognostic evaluation of assumptions used by cumulus parameterizations, Mon. Weather Rev., 121, 2814-2832, 1993.

Grell, G. A., Dudhia, J. and Stauffer, D. R.: A description of the fifth-generation Penn State-NCAR Mesoscale Model (MM5). NCAR Tech. Note NCAR/TN-398+STR, National Center for Atmospheric Research, Boulder, Colorado, 122, 1994.

Helmert, J., Heinold, B., Tegen, I., Hellmuth, O., and Wendisch, M.: on the direct and semidirect effects of Saharan dust over Europe: A modeling study, J. Geeophys. Res., 112, D13208, doi:10.1029/2006JD007444, 2007.

Heinold, B., Helmert, J., Hellmuth, O., Wolke, R., Ansmann, A., Marticorena, B., Laurent, B., and Tegen, I.: Regional modeling of Saharan dust events using LM-MUSCAT: Model description and case studies, J. Geophys. Res., 112, D11204, doi:10.1029/2006JD007443, 2007.

Hesse, M., Kopke, P., and Schult, I: Optical properties of aerosols and clouds: The software package OPAC, B. Am. Meteorol. Soc., 79, 831-844, 1998.

Holtslag, A. A. M., de Bruijn, E. I. F., and Pan, H. L.: A high resolution air mass transformation model for short-range weather forecasting, Mon. Wea. Rev., 118, 1561-1575, 1990.

Kalnay, E., Kanamitsu, M., Kistler, R., et al.: The NCEP/NCAR 40Year Reanalysis Project, Bull. Am. Meteorol. Soc., 77, 437-471, doi:10.1175/1520-0477, 1996.

Kiehl, J. T., Hack, J., Bonan, G., et al.: Description of the NCAR Community Climate Model (CCM3), NCAR Technical Notes, NCAR/TN-420+STR, 152 pp., 1996.

King, M. D., Kaufman, Y. J., Menzel, W. P., and Tanré, D.: Remote Sensing of Cloud, Aerosol and Water Vapor Properties from the Moderate Resolution Imaging Spectroradiometer (MODIS), IEEE T. Geosci. Remote, 30, 1-27, 1992.

Konare, A., Zakey, A. S., Giorgi, F., Rauscher, S., Ibrah, S. and Bi, $\mathrm{X}$. : A regional climate modeling study of the effect of desert dust on the West African monsoon, J. Geophys. Res., 113, D12206, doi:10.1029/2007JD009322, 2008.

Lelieveld, J., Berresheim, H., Borrmann, S., Crutzen, P. J., Dentener, F. J. and co-authors: Global air pollution crossroads over the Mediterranean, Science, 298, 794-799, 2002.

Marticorena, B. and Bergametti, G.: Modeling the atmospheric dust cycle: 1 . Design of a soil derived dust emission scheme, J. Geophys. Res., 100, 16415-16430, 1995.

Meloni, D., di Sarra, A., Di Iorio, T., and Fiocco, G.: Influence of the vertical profile of Sahara dust on the visible direct radiative forcing, J. Quant. Spectrosc. Ra., 93, 397-413, 2005.

Meloni, D., di Sarra, A., Di Iorio, T., and Fiocco, G.: Direct radiative forcing of Saharan dust in the Mediterranean from measurements at Lampedusa Island and MISR space-borne observations, J. Geophys. Res., 109, D08206, doi:10.1029/2003JD003960, 2004.

Pal, J. S., Small, E. E. and Elthair, E. A. B.: Simulation of regionalscale water and energy budgets:Representation of subgrid cloud and precipitation processes within RegCM, J. Geophys. Res., 105, 29579-29594, 2000.

Pal, J. S., Giorgi, F., Bi, X., Elguindi, N., Solmon, F., Gao, X., Rauscher, S. A., Francisco, R., Zakey, A., Winter, J., Ashfaq, M., Syed, F. S., Bell, J. L., Diffenbaugh, N. S., Karmacharya, J., Konare, A., Martinez, D., da Rocha, R. P., Sloan, L. C. and Steiner, A.: Regional climate modelling for the developing world: The ICPT RegCM3 and RegCNER, Bull. Atm. Meteorol. Soc., 88(9), 1395-1409, 2007.

Pavese, G., De Tomasi, F., Calvello, M., Esposito, F., and Perrone, M. R.: Detection of Sahara dust intrusions during mixed advection patterns over south-east Italy: A case study, Atmos. Res., 92, 489-504, 2009.

Perez, C., Nickovic, S., Pejanovic, G., Baldasano, J. M., and Ozsoy, E.: Interactive dust-radiation modeling: A step to improve weather forecasts, J. Geophys. Res., 111, D16206, doi:10.1029/2005JD006717, 2006.

Santese, M., De Tomasi, F., and Perrone, M. R.: Advection patterns and aerosol optical and microphysical properties by AERONET over south-east Italy in the central Mediterranean, Atmos. Chem. Phys., 8, 1881-1896, 2008,

http://www.atmos-chem-phys.net/8/1881/2008/.

Sokolik, I. N., Winker, D. M., Bergametti, G., Gilette, D. A., Carmichael, G., Kaufman, Y., Gomes, L., Schuetz, L., and Penner, J. E.: Introduction to special section: Outstanding problems in quantifying the radiative impacts of mineral dust, J. Geophys. Res., 106, 18015-18028, 2001.

Solmon, F., Giorgi, F., and Liousse, C.: Aerosol modeling for regional climate studies: application to anthropogenic particles and evaluation over a European/African domain, Tellus, 58B, 51-72, 2006.

Tafuro, A. M., Banaba, F., De Tomasi, F., Perrone, M. R., and Gobbi, G. P.: Saharan dust particle properties over the central Mediterranean, Atmos. Res., 81, 67-93, 2006.

Tafuro, A. M., Kinne, S., De Tomasi, F., Perrone, M.: Annual cycle of aerosol direct radiative effect over southeast Italy and sensitivity studies, J. Geophys. Res., 112, ISSN:0148-0227, 
doi:10.1029/2006JD008265, 2007.

Tafuro, A., De Tomasi, F., and Perrone, M. R.: Remote sensing of aerosols by sunphotometers and lidar tecniques, in: Advanced Environmental monitoring, edied by: Kim, Y. J. and Platt, U., Springer, ISBN:978-1-4020-63636-3, chapter 14, vol. XXII, 422, 2008.

Tegen, I. : Modeling the mineral dust aerosol cycle in the climate system, Quaternary Science Reviews, 22(18,19), 1821-1834, doi:10.1016/S0277-3791(03)00163-X, 2003.

Todd, M. C., bou Karam, D., Cavazos, C., Bouet, C., Heinold, B., Baldasano, J. M., Cautenet, G., Koren, I., Perez., C., Solmon, F., Tegen, I., tulet., P., Washington, R., and Zakey, A.: Quantifyng uncertainty in estimates of mineral dust flux: An intercoparison of model performance over the Bodele Depression, northern Chad, J. Geophys. Res., 113, D24107, doi:10.1029/2008JD010476, 2008.

Yu, H., Kaufman, Y. J., Chin, M., Feingold, G., Remer, L. A., Anderson, T. L., Balkanski, Y., Bellouin, N., Boucher, O., Christopher, S., DeCola, P., Kahn, R., Koch, D., Loeb, N., Reddy, M. S., Schulz, M., Takemura, T., and Zhou, M.: A review of measurement-based assessments of the aerosol direct radiative effect and forcing, Atmos. Chem. Phys., 6, 613-666, 2006, http://www.atmos-chem-phys.net/6/613/2006/.
USDA: Soil taxonomy, a basic system of Soil Classification for making and interpreting Soil Surveys, US Government Printing Office, Washington, USA, 869 pp., 1999.

Wang, H., Shi, G. Y., Li, S. Y., Li, W., Wang, B., and Huang, Y. B.: The impacts of optical properties on radiative forcing due to dust aerosol, Adv. Atmos. Sci., 2393, 431-441, 2006.

Zakey, A. S., Solmon, F., and Giorgi, F.: Implementation and testing of a desert dust module in a regional climate model, Atmos. Chem. Phys., 6, 4687-4704, 2006, http://www.atmos-chem-phys.net/6/4687/2006/.

Zhang, D. F., Zakey, A. S., Gao, X. J., Giorgi, F., and Solmon, F.: Simulation of dust aerosol and its regional feedbacks over East Asia using a regional climate model, Atmos. Chem. Phys., 9, 1095-1110, 2009,

http://www.atmos-chem-phys.net/9/1095/2009/. 